BULLETIN Bulletin hispanique

HispaniQuE Université Michel de Montaigne Bordeaux

114-1 | 2012

Varia

\title{
Conceptualización de la luz en verbos derivados de lumen
}

Hilde Hanegreefs y Jorge Fernández Jaén

\section{CpenEdition}

Journals

Edición electrónica

URL: http://journals.openedition.org/bulletinhispanique/1881

DOI: 10.4000/bulletinhispanique.1881

ISSN: 1775-3821

Editor

Presses universitaires de Bordeaux

Edición impresa

Fecha de publicación: 1 junio 2012

Paginación: 307-343

ISBN: 978-2-86781-812-7

ISSN: 0007-4640

Referencia electrónica

Hilde Hanegreefs y Jorge Fernández Jaén, « Conceptualización de la luz en verbos derivados de lumen », Bulletin hispanique [En línea], 114-1 | 2012, Publicado el 01 junio 2015, consultado el 19 abril 2019.

URL : http://journals.openedition.org/bulletinhispanique/1881; DOI : 10.4000/bulletinhispanique.1881 


\title{
Conceptualización de la luz en verbos derivados de lumen
}

\author{
Hilde Hanegreefs \\ Lessius/K.U.Leuven - Bélgica \\ JoRge FernándeZ JaÉN \\ Universidad de Alicante - España
}

Cet article propose l'analyse cognitive de cinq verbes dénominaux (provenant $d u$ lexème latin lumen): iluminar «illuminer», alumbrar "éclairer», deslumbrar "éblouir», vislumbrar «entrevoir» et columbrar "apercevoir». En dépit du fait qu'ils partagent de nombreux traits sémantiques et formels (dus à leur relation directe avec le concept de LUMIËRE), chacun de ces verbes conceptualise différents aspects du domaine universel de la LUMIËRE. L'objet de cette étude est de mettre en relief ces divers aspects.

Este artículo propone un análisis cognitivo de cinco verbos denominales: iluminar, alumbrar, deslumbrar, vislumbrar y columbrar. Si bien estos verbos comparten el étimo latino lumen, no son sinónimos. Pese a coincidir en muchos de sus rasgos semánticos y formales - debido a que todos están directamente vinculados a la noción de la LUZ-, cada uno de los verbos conceptualiza aspectos diferentes del dominio universal de la LUZ. Esos aspectos son los que tratamos de recalcar en nuestro estudio.

Thispapershows why the following five Spanish denominal verbs: iluminar - «illuminate», alumbrar - «light», deslumbrar - «dazzle», vislumbrar - discern y columbrar - «make out», in spite of their common Latin stem "lumen», cannot be regarded as synonymous. A thorough corpus analysis reveals that, beyond the semantic and formal features they have in common (due to the direct connection with the concept of LIGHT), each verb conceptualizes different aspects of the pre conceptual primitive LIGHT. The present study aims at stressing those diverse aspects.

Mots-clés : dérivation, verbes de perception, lumière, analyse de corpus, linguistique cognitive. 


\section{A DIFERENCIACIÓN FORMAL, CONCEPTUALIZACIÓN DIFERENTE}

Nos proponemos en este trabajo analizar cinco verbos españoles relacionados con la percepción y la causatividad, a saber, los verbos iluminar, alumbrar, deslumbrar, vislumbrar y columbrar. Aunque aparentemente pueda intuirse que estos cinco términos son prácticamente sinónimos, lo cierto es que una exploración detallada de su funcionamiento demuestra que no lo son. Ciertamente, los cinco verbos comparten un denominador común de naturaleza etimológica, puesto que todos se relacionan con el sustantivo latino lumen (LUz). Sin embargo, este origen compartido ha permitido que, pese a coincidir en muchos de sus rasgos semánticos y formales, cada uno de los verbos haya desarrollado matices específicos que justifican su existencia en el código lingüístico.

Nos inspiramos en la Lingüística Cognitiva (en adelante LC) al asumir como base de este estudio la idea de que la simple existencia de diversidad léxica es indicio suficiente de que cada uno de los lexemas entrańa una conceptualización diferente. En las páginas que siguen procederemos de forma inductiva estudiando un corpus de datos con el fin de dar respuesta a una serie de hipótesis.

Primero, rechazamos la idea de sinonimia total. Las diferencias construccionales detectadas en el corpus reflejan necesariamente diferencias conceptuales en la experiencia humana (Lakoff 1987, Achard 1998, Taylor 2003), lo que, por ende, justifica las diferencias semánticas que cada verbo mantiene con respecto a los demás (Langacker 1987, 1991, 1999).

Segundo, si bien es cierto que el sustantivo de partida de estos verbos habrá condicionado los significados que han desarrollado, ese núcleo semántico (lumen o LUz), asimismo, conectará estos verbos con ciertos patrones universales de concepción de la realidad. Aquí cabe señalar la función estructural de la metáfora y la metonimia como nexos fundamentales entre los significados concretos y abstractos que ayudan a revelar la particular conceptualización e interpretación de un verbo (Lakoff \& Johnson 1980, Croft \& Cruse 2004).

Tercero, las distintas conceptualizaciones que pueden expresar estos verbos no serán equivalentes, sino que -según el axioma de las categorías radiales con prototipicidad-algunas serán más prototípicas que otras (Brugman \& Lakoff 1988, Cuenca \& Hilferty 1999, Geeraerts 2006). Esta prototipicidad está motivada por factores semánticos y pragmáticos.

En fin, pensamos que entre iluminar, alumbrar, deslumbrar, columbrar y vislumbrar existen relaciones de parentesco y disimilitud que permiten diseñar un continuo entre ellos, que iría desde un polo causativo (expresión de una fuerza que genera un estado) hasta un polo perceptivo (captación de un fenómeno de la realidad). Así, el campo conceptual de la LUZ posibilita la existencia de múltiples verbos capaces de codificar numerosos dominios de la experiencia cognitiva de los hablantes.

Con el objetivo de llegar a entender mejor el interés de los verbos de percepción en el estudio de la lengua, nos detenemos primero en los verbos de 
percepción como categoría lingüística (apartado 2), antes de pasar al análisis detallado de los ejemplos del corpus (apartado 3).

\section{LOS VERBOS DE PERCEPCIÓN COMO CATEGORÍA LINGÜÚSTICA}

Los verbos de percepción física son unidades léxicas que se encargan de expresar lingüísticamente el contacto con el entorno que se realiza mediante los cinco sentidos corporales, por lo que hay verbos de percepción visual, auditiva, táctil, olfativa y gustativa. Estos verbos constituyen un dominio conceptual especialmente interesante para la lingüística en general y para la LC en particular porque su estudio pone en evidencia la fuerte interacción que existe entre la experiencia sensorial, el lenguaje y la cognición ${ }^{1}$. Pasamos brevemente revista a tres problemas clásicos asociados a los verbos de percepción.

El primer problema que plantean es el de cómo clasificarlos desde un punto de vista gramatical, puesto que su comportamiento morfosintáctico es tan heterogéneo que resulta muy difícil establecer una clasificación única para acotarlos. En efecto, estos verbos pueden expresar todo tipo de predicaciones, pueden funcionar como verbos auxiliares, como verbos pseudo-copulativos e incluso como marcadores discursivos. Admiten toda clase de complementos, tales como complementos nominales (concretos o abstractos), cláusulas de infinitivo y gerundio, oraciones completivas, interrogativas indirectas, etc. En cuanto a su valor semántico, los verbos de percepción se encuentran entre los verbos más elementales de todas las lenguas (y, por tanto, entre los más usados) lo que explica que suelan ser polisémicos. Por todo ello, los verbos de percepción física, y muy particularmente los de visión y audición, son unidades lingüísticas de una gran complejidad.

Basándose en datos procedentes de numerosas lenguas del mundo, Viberg (1984) propuso una de las taxonomías de los verbos de percepción más conocidas, en virtud de la cual habría tres tipos básicos de verbos de percepción: verbos de percepción activa, verbos de percepción pura (o verbos de experiencia) y verbos de percepción copulativa ${ }^{2}$. De este modo, los verbos de percepción activa representan un evento de actividad, en el que tenemos un sujeto animado que realiza voluntariamente una acción con alguno de sus órganos perceptivos durante un determinado período de tiempo con el fin de examinar un concreto estímulo. Ejemplos españoles de verbos de percepción activa de diferentes sentidos serían mirar (vista), saborear (gusto) o acariciar (tacto).

1. Para una aproximación actualizada a las múltiples y complejas propiedades de los verbos de percepción se pueden consultar, entre otros, los siguientes trabajos: Ibarretxe-Antuñano (1999, 2003, 2008), Rodríguez Espińeira (2000, 2004), Roegiest (2003), Soares da Silva (2004), García-Miguel (2005), Grezka (2006), Fernández Jaén (2006, 2008), Enghels (2007), Hanegreefs (2008).

2. Como señala Horno Chéliz (2008), esta tipología se fundamenta en la teoría aspectual de los eventos defendida por primera vez en el trabajo clásico de Vendler (1967). 
Los verbos de percepción pura representan aspectualmente un logro, no una actividad. Por ello en estos casos nos encontramos con un evento de experiencia involuntaria, en el que un sujeto percibe un estímulo sin pretenderlo. Estas percepciones se producen cuando un estímulo alcanza un órgano corporal y dicho órgano lo descifra de forma espontánea, sin que el sujeto pueda evitarlo. Ejemplos de este tipo los tenemos en el verbo sentir, verbo multimodal que puede expresar prácticamente cualquier percepción sensorial, y en muchos ejemplos de ver y oir?

Por último, los verbos de percepción copulativa representan un estado y no estrictamente un evento. Esta posibilidad se subdivide a su vez en dos tipos. Por un lado los verbos de percepción copulativa pueden conceptualizar una capacidad del sujeto, la capacidad de poseer determinado sentido. Es lo que sucede en una oración como Paula no oye sin su audífono, en la que oír lexicaliza la capacidad de la audición. Por otra parte, estos verbos también pueden tener un sujeto sintáctico que representa al estímulo sensorial. En estos casos el verbo posee una estructura intransitiva en la que se focaliza la presencia del estímulo y su propia potencialidad para ser percibido, quedando el perceptor fuera de la escena, simplemente relegado al papel de conceptualizador (C). Es lo que sucede en oraciones como Esta canción se oye bien, Desde aqui se ve la montaña o La camisa huele a rosas, en las que los sujetos canción, montaña y camisa representan los objetos que pueden ser percibidos por el oído, la vista o el olfato.

Esta clasificación no debe tomarse como algo cerrado sino más bien como un continuo de fronteras difusas en el que los distintos tipos a veces se superponen. De hecho, muy frecuentemente los verbos de percepción pueden encajar en varios de esos grupos, o en los tres. Esta flexibilidad viene motivada por la propia naturaleza semántica de los verbos de percepción y por las condiciones pragmáticas que pautan el uso que los hablantes hacen de ellos.

En toda escena de percepción podemos encontrar una serie de elementos recurrentes. En primer lugar un PERCEPTOR, es decir, una entidad animada (y habitualmente humana) que percibe algo a través de alguno de sus sentidos. También hay un PERCEPTO ${ }^{4}$, el objeto o estímulo sensorial percibido por el perceptor. A esto hay que añadir un factor de Distancia (Bat-Zeev Shyldkrot 1989, Talmy 2000), la distancia que media entre perceptor y percepto; esa distancia puede condicionar la percepción e incluso anularla. Por ejemplo, para oír algo quizá pueda haber cierta distancia, pero para escucharlo la distancia ha de ser menor. Además, el espacio físico que separa a perceptor y percepto posibilita que ciertos verbos de la visión como mirar hayan desarrollado estructuras preposicionales que representan la trayectoria espacial que recorre la mirada

3. Los verbos ver y oír pueden expresar en español tanto percepción activa como percepción pura. Puede verse un análisis sintáctico de este fenómeno en Fernández Jaén (2006).

4. Tomamos el término percepto (percept) de Bolinger (1974). Ya ha sido utilizado en español por varios autores, entre otros Demonte (1991: 40), Rodríguez Espiñeira (2000: 47) y Cuartero Otal (2003: 75). 
hasta alcanzar el percepto (Hanegreefs 2007, 2008). Por tanto, la percepción no es estable, sino que fluctúa debido a las condiciones contextuales en que se produce, las cuales pueden condicionarla notablemente. A veces el perceptor controla totalmente la situación y puede escudrińar el percepto con toda comodidad. En otras ocasiones el percepto es huidizo, o breve, o esporádico, lo que complica su aprehensión, del mismo modo que a veces la distancia cancela las posibilidades de éxito del perceptor, por ejemplo si se quiere mirar algo que está muy lejos. A esto hay que añadir que cada sentido físico tiene sus propias particularidades fisiológicas, lo que termina de demostrar que resulta muy difícil establecer un único patrón de funcionamiento para los sentidos como para los verbos conexos.

Una segunda cuestión muy debatida en la literatura sobre los verbos de percepción es la de cómo asignar papeles semánticos al perceptor y al percepto, problema que se relaciona a su vez con el modo en que se materializan estos dos conceptos sintácticamente. En principio parece lógico que el PERCEPTOR se identifique con el proto-rol de PROTO-AGENTE, mientras que el PERCEPTo se correspondería con un proto-Paciente (Dowty 1991). Para Dowty un PROTO-AGENTE representa conceptualmente a una entidad que se caracteriza por tener control sobre una acción, por tener una intención, por ser causa de un evento y por tener una existencia independiente de ese evento. Por su parte, el PROTO-PACIENTE representaría a la entidad controlada y afectada por el evento, entidad que puede verse alterada físicamente por el PROTO-AGENTE. Por tanto, la relación entre estos dos proto-roles es asimétrica; uno de ellos, el agentivo, posee mayor prominencia conceptual que el otro. Naturalmente, en el plano sintáctico, el PROTO-AGENTE suele ser el sujeto sintáctico y el PROTOPaCiente tiende a funcionar como Complemento Directo (CD). Veamos algunos ejemplos:
1) Sonia saboreó el helado con mucho placer.
2) Luis tocó tanto el jarrón que acabó rompiéndolo.
3) El sumiller degustó los vinos para poder elegir el más apropiado.

Como se puede apreciar, en estos casos encontramos tres sujetos sintácticos (Sonia, Luis y el sumiller) que encajan perfectamente en la noción teórica del proto-agente: los tres son el motor de la predicación, controlan la acción por completo (hasta el punto de que pueden ser responsables de sus consecuencias, como se ve en el ejemplo (2) en el que la oración consecutiva que acabó rompiéndolo deriva de la acción previa de tocar) y tienen una intención, lo que hace que incluso pueda haber una oración subordinada de finalidad complementando la predicación principal, como ocurre en (3). A su vez, los CC.DD. el helado, el jarrón y los vinos serían los proto-pacientes, puesto que se encuentran en una situación total de subordinación y cambian de estado (en un sentido físico) tras la acción perceptiva. Pero lo cierto es que fuera de los casos más prototípicos con verbos del tacto y del gusto, esta idealización esquemática no siempre es tan clara. Observemos las siguientes oraciones: 
4) Geoffrey vio el partido de fútbol en su casa.

5) El estudiante ha mirado el cuadro durante una hora.

6) A Carolina le encanta escuchar buena música.

7) En cuanto abrí la puerta olí el perfume que llevabas.

En estos casos la relación entre perceptor y percepto es menos típica. De entrada, ninguno de los sujetos sintácticos (Geoffrey, el estudiante, Carolina o el sujeto elidido yo) realiza ninguna acción en sentido estricto, puesto que su vinculación con el evento es más abstracta. Es cierto que los sujetos de (4), (5) y (6) tienen una intención (disfrutar del partido, analizar el cuadro o deleitarse con la música), pero para llevarla a cabo no actúan en un sentido literal, o al menos su actuación no es evidente. El caso de (7) es aún menos prototípico porque no hay ningún tipo de intencionalidad, y el evento tiene una duración mínima ya que oler algo de forma inesperada se conceptualiza como un logro instantáneo en el que el sujeto no puede intervenir (Fernández Jaén 2008). Por su parte, los perceptos partido de fútbol, el cuadro, la buena música y el perfume tampoco se corresponden con un auténtico proto-paciente puesto que no se ven afectados por la acción sensorial en ningún grado y existen con total independencia de que sean percibidos o no.

En ocasiones, los perceptos resultan tan ajenos al perceptor o son tan difíciles de detectar debido a las condiciones pragmáticas que la oración tiende a conceptualizarse de un modo distinto, tal y como se ejemplifica a continuación:

8) Desde aquí se ve la catedral.

9) La cima fue vista por el escalador tras superar el campamento base.

10) De madrugada aún se oían las notas de la orquesta.

11) La cocina huele a quemado.

Todas estas oraciones se corresponden con lo que Viberg (1984) llama percepción copulativa con sujeto-estímulo, percepción de carácter estativo: los sujetos sintácticos la catedral, la cima, las notas de la orquesta y la cocina representan a los perceptos semánticos. ¿Por qué aquí el percepto se conceptualiza como sujeto sintáctico? ¿Dónde queda entonces el perceptor? En estos casos el perceptor entiende en el plano experiencial que el estímulo es incontrolable y que percibirlo no depende en absoluto de él. La oración de (8) podría muy bien emitirse desde una habitación de hotel desde la que es visible una catedral, pero resultaría anómala si el hablante la emitiera delante mismo de la catedral; delante de ella controlaría la percepción visual (por lo que usaría una estructura transitiva como la de (4)) mientras que, desde la habitación, que la catedral quede a la vista o no es una eventualidad que no depende del perceptor, por lo que la escena se configura de modo que el propio estímulo visual es el sujeto, 
quedando el perceptor en segundo plano, fuera de escena. Lo mismo ocurre en (9), sólo que en este caso la posibilidad de ver la cima depende de una condición concreta (superar el campamento base), por lo que a partir de ese paso la percepción será posible, e incluso parcialmente controlable ${ }^{5}$. En (10) las notas musicales son audibles incluso desde lejos sin que el perceptor pueda evitarlo, mientras que en (11) el olor que despide la cocina invade el espacio físico y alcanza a quien pase por allí de forma totalmente aleatoria.

Por todo ello, resulta operativa la escala de agentividad de Van Valin \& LaPolla (1997) en virtud de la cual el papel temático del sujeto sintáctico con los verbos de percepción es gradual, pudiendo ir de lo más agentivo (un AGENTE), hasta lo más inagentivo (el ESTímulo o el PACIENTE), habiendo casos intermedios. Además esta escala encaja con las propiedades prototípicas de los proto-roles de Dowty y con sus consecuencias aspectuales: cuanto más se acerca el sujeto al proto-agente, mayor control y transitividad (acciones) y cuanto más se acerca al proto-paciente, menor control y tendencia a la intransitividad (estados), tal y como se aprecia en la Figura 1:

\begin{tabular}{|c|c|c|}
\hline $\begin{array}{l}\text { + agentivo } \\
+ \text { control } \\
+ \text { transitivo }\end{array}$ & & $\begin{array}{l}\text { - agentivo } \\
\text { - control } \\
\text { - transitivo }\end{array}$ \\
\hline \multicolumn{3}{|c|}{ AGENTE $<$ OBSERVADOR $<$ PERCEPTOR $<$ OBJETIVO/ESTÍMULO $<$ PACIENTE } \\
\hline ACTIVIDADES & LOGROS & ESTADOS \\
\hline
\end{tabular}

Fig. 1. - La escala de agentividad con verbos de percepción

Esta concepción continua de la agentividad con la percepción sensorial explica adecuadamente todos los casos. Los eventos de percepción del tipo tocar, saborear o degustar estarían en el extremo izquierdo de la escala, al ser acciones prototípicas. Verbos como mirar o escuchar serían también altamente agentivos (puesto que focalizan la atención voluntaria que mantiene el perceptor con respecto al estímulo), aunque sus acciones resultarían un poco menos prototípicas al no quedar afectado el percepto, por lo que en estos casos los sujetos actuarían como observadores. Ver y oir se hallarían en una

5. Por esa razón la oración de (8) es una pasiva refleja y la de (9) una pasiva auxiliada con complemento agente (el escalador). En percepciones visuales y auditivas de tipo copulativo las pasivas reflejas indican estados, es decir, indican que un estímulo existe de forma durativa (sin límites temporales definidos) y que puede percibirse si se dan las condiciones necesarias, mientras que las pasivas auxiliadas expresan logros, percepciones que se dan de forma automática en cuanto se cumple una determinada condición; una vez satisfecha dicha condición (superar el campamento base), el perceptor puede ejercer cierto control sobre la acción perceptiva (en cuanto el escalador ve la cima tras superar el campamento es libre de recrearse en su contemplación), por lo que puede aparecer opcionalmente en forma de complemento agente. Para un detallado análisis de estas estructuras, véanse los trabajos de Fernández Lagunilla (2006) y Horno Chéliz (2008). 
zona intermedia, que fluctuaría, según el caso, entre lo bastante agentivo y lo totalmente inagentivo ${ }^{6}$. Por último, oler, tiende a estar en el extremo derecho, debido a que el olfato es el sentido menos controlado en el ser humano, por lo que su configuración prototípica es intransitiva, aunque también puede aparecer esporádicamente con estructuras transitivas (como las de (7)) ${ }^{7}$.

Una tercera cuestión muy discutida ha sido la de los universales semánticos de la percepción. Habida cuenta de que las propiedades fisiológicas y biológicas implicadas en los procesos perceptivos son las mismas en todas las personas del mundo, ¿cabe esperar que haya cierta universalidad en las proyecciones metafóricas que los verbos perceptivos generan? Sweetser (1990) propuso un conocido inventario de cambios semánticos en lenguas indoeuropeas que ha sido aceptado como válido en numerosas lenguas del mundo. Para Sweetser, la visión se asocia a campos como el cONOCIMIENTO y el CONTROL, mientras que los verbos de la audición suelen expresar metafóricamente tanto CONOCIMIENTO como obEDIENCIA, ya que oír algo y comprenderlo suele comportar una determinada reacción (idea de obediencia). El tacto, sin embargo, propende a nociones como la EMOCión, es decir, ideas mucho más subjetivas que las que generan los sentidos de la vista y el oído. Por último, los sentidos del olfato y el gusto se relacionan con la EMOCión y la EVOCACión, es decir, con los recuerdos y los sentimientos. Estas metáforas, prácticamente universales ${ }^{8}$, tienen una fuerte motivación biológica; los ojos y los oídos son los órganos que más nos ayudan a conocer el mundo, por lo que no es extraño que los verbos relacionados con esos sentidos suelan codificar contenidos epistémicos. En contra, la piel, el olfato y el sentido del gusto nos muestran la realidad de un modo más difuso, en el que la interpretación subjetiva es mayor.

Como hemos comprobado, los verbos de percepción conforman una categoría lingüística especialmente heterogénea, caracterizada por su complejidad estructural y por su riqueza semántica. En los apartados que siguen analizaremos los cinco verbos que constituyen nuestro objeto de estudio con el fin de explicar cuáles son sus propiedades y qué lugar ocupan en el marco general de los verbos de percepción.

\section{De LA INFORMACión LEXICOGRÁficA AL BANCO DE DATOS CREA}

Los verbos iluminar, alumbrar, deslumbrar, vislumbrar y columbrar son todos verbos denominales, es decir, son términos creados morfológicamente mediante un proceso de parasíntesis a partir de una base previa de naturaleza

6. Naturalmente, en los casos de percepción pura el sujeto funcionaría simplemente como PERCEPTOR, al carecer por completo de intención y control.

7. A esta conclusión llegan los análisis estadísticos de Fernández Jaén (2008).

8. Existen lenguas que alteran esta distribución metafórica, por lo que puede afirmarse que no es totalmente universal. Por ejemplo hay culturas en las que el CONOCIMIENTo tiende a expresarse a partir de verbos relacionados con el olfato y el gusto. Sobre esta cuestión pueden consultarse los trabajos de Danesi $(1985,1990)$ y de Ibarretxe-Antuñano (2008). 
nominal, un sustantivo. En el caso de nuestros verbos, todos proceden (de un modo directo o indirecto) del vocablo latino, lumen $^{9}$, que en latín poseía el significado de Luz y, por diversas extensiones metonímicas, también otros como «luz del día», «día», «lámpara», "vela», «ventana» (lugar por donde entra la luz), «claridad» o «resplandor». A su vez, en un plano metafórico, lumen también podía significar «ojos», "luz de los ojos» o «adorno» (lo que es bello por tener luz). Esta variedad semántica emana del concepto general de lo luminiscente; la LUZ es una categoría cognitiva primaria en nuestra concepción del mundo, un auténtico universal antropológico. El ser humano es una criatura esencialmente visual que ha dependido mucho de su vista a lo largo de su evolución: la vista es decisiva tanto para cazar como para defenderse, y los ojos humanos no pueden ver sin luz (Fernández Jaén 2008, Ballester 2009). Por este motivo no es de extrańar que este sencillo término, lumen, pueda evocar una gama tan rica de conceptos, algunos de los cuales están relacionados directamente con experiencias muy antiguas.

¿Cómo se plasman esas ideas en nuestros verbos? Cada uno de ellos ha lexicalizado de un modo particular alguna de las posibles ramificaciones del sustantivo de partida. Basta para comprobarlo con examinar las diferentes acepciones que el DEA (Diccionario del Español Actual) de Seco (1999) ofrece de estos términos:

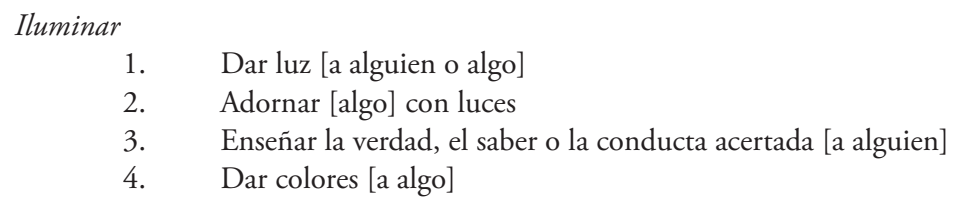

Alumbrar

1. Proyectar luz [sobre un lugar]

2. Encender [una luz] o hacer que luzca

3. Parir [un hijo]

4. Descubrir y sacar a la superficie [algo que estaba bajo tierra]

5. Sacar a la luz o poner de manifiesto [algo]

6. Brillar o lucir (intransitivo)

7. Nacer (intransitivo)

8. Emborracharse (intransitivo)

Deslumbrar

1. Dejar momentáneamente sin vista [a alguien] una luz muy intensa, o alguien o algo que la produce o refleja

2. Admirar o impresionar vivamente [a alguien] el esplendor o la brillantez o alguien o algo que los posee.

9. De lumen procede el sustantivo español lumbre, término que durante la Edad Media significaba CUERPO QUE DESPIDE LUZ, hasta que por un proceso de concreción semántica pasó a significar LLAMA o FUEgo (Corominas \& Pascual 1980-1991). 
Columbrar

1. Divisar o ver desde lejos con poca nitidez

2. Ver o percibir [algo]

3. Adivinar [algo] por indicios

Vislumbrar

1. Ver de manera imprecisa

Este examen de la información lexicográfica del DEA invita a hacer algunas reflexiones. Según la lista de significados, parece que alumbrar es más frecuente que el resto, debido a su mayor polisemia. También se observa que pese a tener un origen común y diversos componentes relacionados, hay modulaciones diferentes en cada uno. Esas extensiones, ¿̇son específicas de cada verbo o pueden ser lexicalizadas por cualquiera de ellos? ¿Qué hay de común realmente y qué de distinto en estos términos? Algunos de estos verbos también se vinculan a la causatividad (hacer que algo tenga luz) mientras que otros como columbrar o vislumbrar son claramente verbos de percepción visual. ¿Es eso realmente así? Además, hay estructuras sintácticas que no están representadas en esa lista. ¿Se utilizan actualmente en español o no?

Para responder a todas estas cuestiones hemos analizado diversas muestras aleatorias de ocurrencias reales de nuestros cinco verbos utilizando la base de datos CREA (Corpus de Referencia del Español Actual ${ }^{10}$ ). Además, hemos restringido el corpus en cuanto a región (España) y género (literatura, prensa y textos orales), lo que genera la siguiente frecuencia absoluta de casos:

\begin{tabular}{lrccc} 
& LITERATURA & PRENSA & ORAL & Total \\
\hline Iluminar & 1343 & 204 & 26 & 1573 \\
\hline Alumbrar & 286 & 64 & 12 & 362 \\
\hline Deslumbrar & 265 & 58 & 9 & 332 \\
\hline Vislumbrar & 57 & 44 & 3 & 104 \\
\hline Columbrar & 21 & 1 & - & 22
\end{tabular}

Tabla 1. - Frecuencia absoluta de casos

Este cuadro revela un hecho interesante. A diferencia de lo que pudiera pensarse a la vista de la información contenida en los diccionarios, iluminar es con mucha diferencia el verbo más documentado de la serie. Alumbrar y deslumbrar alcanzan cifras semejantes de aparición, mientras que los verbos de percepción visual vislumbrar y columbrar son claramente inusuales en el español de hoy. A continuación pasaremos a analizar de forma individual cada uno de los verbos y expondremos los resultados que arroja nuestra exploración

10. Este corpus, editado por la Real Academia Española, se puede consultar en la página siguiente: www.rae.es. 
empírica. Para ello tomaremos en consideración tanto los postulados de la LC como las pautas de trabajo de los modelos construccionales de análisis lingüístico.

\section{III.1 Iluminar: LUZ ES BELLEZA}

El verbo español iluminar procede del latín illumināre, verbo denominal formado a partir de lumen. La herencia latina hace que iluminar haya desarrollado en español múltiples significados muy semejantes a los que ya tenía su étimo en latín. El núcleo semántico de iluminar es el de PROYECTAR LUZ: una entidad emite una luz que alcanza a otra entidad y hace que automáticamente ésta también tenga luz. Esta imagen conceptual admite diversas conceptualizaciones léxico-construccionales; cada conceptualización muestra cómo el C (el hablante que enuncia desde su punto de vista) construye la escena, estando altamente influido por su propia experiencia sensorial.

Una primera conceptualización (poco frecuente en el corpus) es aquella en la que un sujeto humano proyecta la luz sobre otra entidad (CD), conceptualización que puede simbolizarse como sigue ${ }^{11}$ :

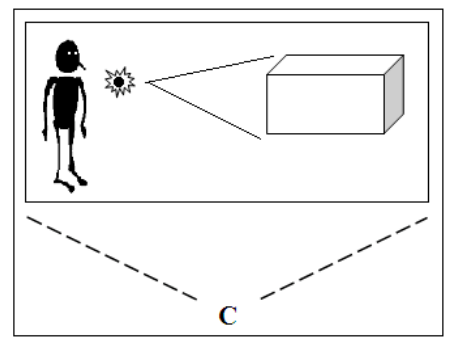

Fig. 2. - Iluminar con sujeto humano (agentivo)

En el ejemplo (12), Beruelo es el agente que intencionadamente proyecta luz sobre algo (en este caso una persona). Puesto que los seres humanos no despedimos luz, esta conceptualización -conforme con el principio de la iconicidad-suele añadir un complemento instrumental que especifica con qué elemento proyecta la luz el sujeto (con la linterna).

12) Tolibio se había puesto de pie ante la pantalla. Beruelo le iluminó con la linterna. (L.M. Díez Rodríguez, El expediente del náufrago, 1992)

Esta misma conceptualización puede emplearse metafóricamente, para expresar significados más abstractos. Si concebimos la metáfora como el vehículo gracias al cual los hablantes pueden transformar su experiencia sensible

11. El rectángulo tridimensional representa genéricamente a la entidad que recibe la luz. Las líneas discontinuas que conectan con el conceptualizador $\mathrm{C}$ indican que éste representa la escena de forma objetiva y externa al proceso (deíxis epistémica). 
en información nocional (Lakoff \& Johnson 1980), la experiencia concreta de iluminar algo físicamente ofrece un patrón gracias al cual puede expresarse un contenido conceptual muy diferente. Así, en el ejemplo (13), todos los componentes antes mencionados se trasladan a un plano metafórico: ahora el sujeto HUMANo no ilumina una entidad física, sino una entidad metafísica (vuestro espiritu) y lo hace no con una linterna sino con un instrumento abstracto de tipo religioso (con la verdad del evangelio). En este ejemplo, esa proyección metafórica le permite al autor explicar el comportamiento que ha de guiar a los buenos ciudadanos; del mismo modo que al iluminar algo ese algo pasa a ser luminoso, la verdad del evangelio puede iluminar metafóricamente el espíritu, haciendo que tenga luz y por tanto, sea más virtuoso. Naturalmente, esta proyección se apoya en la metáfora conceptual LA LUZ ES EL BIEN. La importancia biológica y cultural que la luz tiene hace que represente elementos positivos.

13) Seréis mejores ciudadanos si sabéis iluminar vuestro espíritu con la verdad del evangelio. (J. J. Benítez, Caballo de Troya 1, 1984)

Otra conceptualización prototípica de iluminar (aproximadamente representa el $50 \%$ de las ocurrencias analizadas), es aquella en la que la entidad que ilumina es no humana. En estas ocasiones el sujeto sintáctico se identifica con objetos que poseen luz propia (linternas, lámparas o velas), y también con fenómenos naturales (las estrellas, el sol, la luna, etc.). Naturalmente, en esta construcción el sujeto sintáctico ya no es agentivo, por lo que no suele aparecer ningún tipo de intencionalidad. Ésta sería la representación esquemática de la escena:

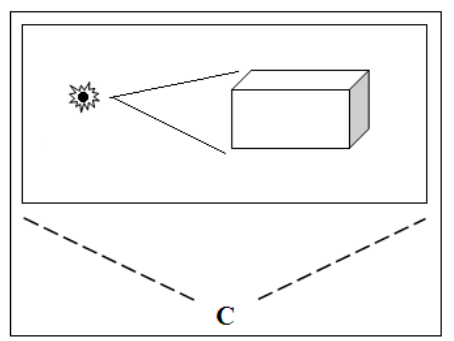

Fig. 3. - Iluminar con sujeto no humano (inagentivo)

Esta conceptualización totalmente inagentiva-SUJETO NO HUMANO PROYECTA LUZ SOBRE ALGO- cuadra perfectamente con la conciencia que los hablantes tienen de la realidad, en la que la aparición de la luz suele ser incontrolable, algo que sucede de modo inopinado o incluso temporalmente programado (como, por ejemplo, la luz del amanecer), del que queda excluido el hablante. Tenemos un ejemplo a continuación:

14) La luz primaveral ilumina el sobrecargado gabinete. (R. Hernández, El secreter del Rey, 1995) 
Esta escena describe un haz de luz que penetra en una determinada estancia siguiendo una pauta natural que ni obedece a intenciones ni es opcional. La luz de la primavera constituye una entidad intrínseca del entorno y $\mathrm{C}$ la codifica como un sujeto sintáctico que se presenta en un determinado momento.

Por supuesto, esta estructura, al igual que la anterior, también admite empleos metafóricos. En (15), el escritor opta por esta conceptualización para explicar en primera persona una situación íntima relacionada con un momento de crisis personal. Los malos pensamientos son el objeto que va a recibir una luz que los va a volver positivos, que los va a mejorar, siendo esa luz una luz divina. En este ejemplo se aprecia perfectamente la oposición metafórica basada en la presencia o ausencia de luz: LA LUZ es lo bUeno y la oscuridad es lo malo. Por ello, los malos pensamientos son tenebrosos y la solución es una luz divina. Además, la experiencia cotidiana que indica que la luz es un fenómeno habitualmente incontrolable que llega inesperadamente perfila el matiz de que la sanación de los pensamientos no depende del C (la primera persona) sino de un proceso más azaroso, de una intervención externa. Como se ve, el esquema se mantiene perfectamente, siendo lo que cambia el dominio semántico.

15) Una lucecita divina ilumina la oscuridad tenebrosa de mis pensamientos. (J. Sierra i Fabra, El regreso de Johnny Pickup, 1995)

Otra posibilidad léxico-construccional, más bien escasa, que admite iluminar tanto con sujeto no humano como con sujeto humano es aquella en la que aparece en la escena un Complemento Indirecto (CI), una entidad (normalmente animada) que se beneficia de la acción verbal. Esta entidad, que se corresponde con lo que Dowty (1991) denomina Proto-RECIPIENTE, es el último eslabón del proceso, la figura en la que se deposita la transferencia de energía de la predicación. Mostramos a continuación la imagen mental básica, tanto con sujeto no humano como con sujeto humano:
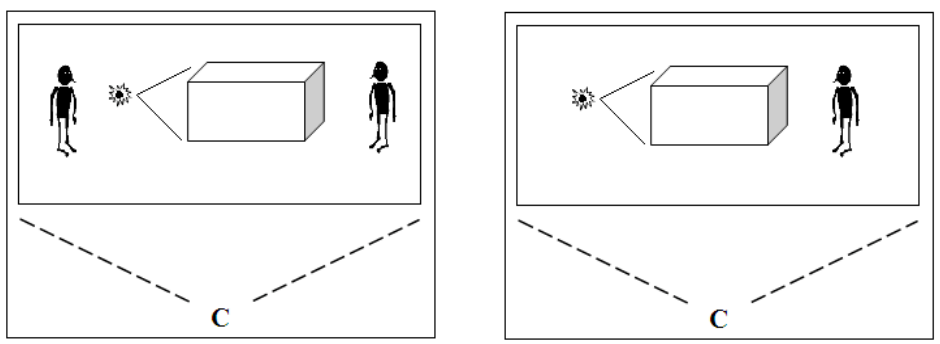

Fig. 4. - Iluminar con sujeto \pm humano y CI

Nuestro análisis muestra inequívocamente que la presencia de un CI en la escena de iluminar es totalmente periférica, incluso con sujetos humanos: el empleo de un instrumento luminoso por parte de una persona raramente está destinado a favorecer a otro individuo, sino que tiene un propósito puntual vinculado a una determinada necesidad del sujeto agente. Cuando el sujeto es 
no humano, la presencia de un beneficiario resulta aún más extraña, habida cuenta de que en estos casos los sujetos de la oración no representan a conceptos animados con voluntad, por lo que la presencia de un beneficiario constituye una contingencia muy esporádica. Veamos algunos de los pocos ejemplos encontrados:

16) [...] al tiempo que el haz de luz de alguna farola le iluminaba el rostro. (J. M. Guelbenzu, El río de la luna, 1981)

17) ¡Y qué terrible cuando esos dioses le iluminaban con sus ojos fosforescentes los sótanos de la memoria! (J. Ferrero, Opium, 1986)

18) [...] desde que tenía memoria, cuando cada tarde le iluminaba la vida la inminencia de la llegada de su padre. (A. Muñoz Molina, Sefarad. Una novela de novelas, 2001)

En el ejemplo (16) hallamos un sujeto no humano (el haz de luz de alguna farola), un CD (el rostro) y un beneficiario expresado por el pronombre clítico le. Como es obvio, con independencia de que el sujeto que recibe en su rostro la luz obtenga de esa circunstancia algún provecho, lo cierto es que el sujeto sintáctico carece de voluntad. Los ejemplos (17) y (18) son de naturaleza metafórica. En (17) una entidad antropomórfica (los dioses) le iluminan con sus ojos fosforescentes (instrumento) los sótanos de la memoria a un proto-recipiente. En este plano abstracto en el que iluminar los sótanos de la memoria significa aproximadamente "hacer recordar» (los recuerdos están en un sótano oscuro y sólo se recuperan si hay luz), sí es admisible una cierta intencionalidad por parte del sujeto agente; los dioses desean que un individuo recuerde, y proyectan luz sobre su pensamiento de forma voluntaria. El caso de (18) es un poco más complejo. En él tenemos un sujeto sintáctico abstracto que no se corresponde con una entidad definida: lo que le ilumina al niño (CI) la vida (CD) es la inminencia de la llegada de su padre. Ese hecho vivido en la infancia y tantas veces presentido hace muy feliz al muchacho, y por eso el escritor expresa esa felicidad con el verbo iluminar, ya que en virtud de la metáfora LA LUZ ES EL BIEN, la vida del niño mejora (tiene más luz y, por tanto, más felicidad) cuando intuye que su padre está a punto de llegar. De todos modos, se deduce de los ejemplos que, para que sea posible la aparición del CI, el CD debe estar relacionado de forma inherente con el CI (proto-recipiente o beneficiario), es decir, que debe ser una propiedad inalienable de este. Así, el rostro, los sótanos de la memoria y la vida pertenecen intrínsecamente al poseedor que expresa el CI.

Uno de los dominios a los que la idea de Luz se aproxima en numerosas culturas del mundo es el de la belleza. Se considera que la luz es bella y que lo que la posee también lo es. Por ello no es de extrañar que en iluminar se haya consumado un cambio semántico en virtud del cual también puede significar «adornar». En estos casos iluminar actúa claramente como un verbo causativo puesto que remite a un proceso destinado a cambiar las propiedades de un objeto; de este modo el sujeto agentivo que ilumina es causa de que un objeto pase a ser hermoso por tener luz. 
En (19), el sujeto femenino ilumina el salón (CD), es decir, hace que esté bonito por tener luces. De este modo, gracias a la metonimia CAUSA POR EFECTO (Peirsman \& Geeraerts 2006), se expresa cómo va a quedar el salón (adornado) enunciando la causa (que tenga luz). Estos casos permiten defender también la existencia de la metáfora conceptual LA LUZ ES BELLEZA.

19) [...] se entregaba en aquellos momentos a la tarea de iluminar el salón - ¿Te gusta?, preguntó, al ver que él la observaba desde fuera. (L. Azancot, Los amores prohibidos, 1980)

Como el dominio de la percepción visual suele relacionarse de manera natural con el conocimiento ${ }^{12}$-según la metáfora COMPRENDER ES VER-iluminar también se desliza hacia contenidos epistémicos: al iluminar metafóricamente algo hacemos que tenga luz, que sea visible y, por tanto, potencialmente comprensible.

En el ejemplo (20), luces se corresponde con INTELigencia ${ }^{13}$ e iluminar con el contenido epistémico de «aclarar» o «enseñar». Estos ejemplos, poco abundantes en el corpus, muestran un proceso intelectivo inspirado por la noción de la luz; ésta es el instrumento para iluminar las cosas y lograr que puedan verse, y si se ven pueden entenderse. De este modo, la sinrazón (objeto abstracto que necesita ser comprendido) puede explicarse a partir de un proceso intelectual que se relaciona con la vista: ILUMINAR > VER > COMPRENDER.

20) Aquel triunfo que tanto pregonaba, no lo era para mí, seguramente porque el Seńor no da a todos el mismo entendimiento, pero mis luces aún alcanzaban a iluminar el camino de su sinrazón. (J. Fernández Santos, Extramuros, 1978)

No obstante, es interesante mencionar que los contenidos epistémicos con iluminar son distintos de los que expresa, por ejemplo, ver. Con ver el conocimiento se concibe como algo instantáneo, resultativo, inequívoco, mientras que con iluminar subyace un proceso más elaborado que requiere de quien comprende un mayor esfuerzo. Si afirmamos, pongamos por caso, que María vio el problema estamos diciendo que María comprendió que había un problema y cuál era su naturaleza en cuanto se dieron una serie de condiciones concretas. En cambio, algo como María iluminó el problema significa que, tras un proceso de reflexión más detenido, María pudo descifrar las claves de dicho problema.

Por último, nuestra exploración de los datos muestra otra variante construccional muy interesante: el uso de iluminar como verbo inacusativo.

12. Así, en español ver posee numerosos empleos de tipo epistémico (Ibarretxe-Antuñano 1999, Fernández Jaén 2006, Hanegreefs 2008), en los que queda de manifiesto lo primaria que es la vista para conocer el mundo.

13. En el español actual siguen siendo muy frecuentes expresiones gramaticalizadas como tener luces o ser una lumbrera para indicar que alguien es muy inteligente. Sobre este tipo de estructuras léxicas puede verse el trabajo de Sabban (1994). 
Como es sabido, un verbo inacusativo es un verbo intransitivo en el que el sujeto sintáctico representa a la entidad no animada que padece o en la que se manifiesta la eventualidad que denota el verbo (Mendikoetxea 1999). Esta conceptualización focaliza la idea de un cambio de estado en la entidad sujeto, y ese cambio de estado, en el caso de iluminar, se produce por un evento de causa interna, ya que no hay ningún agente externo que lo provoque: el cambio se materializa porque alguna propiedad intrínseca del sujeto hace que así ocurra.

En (21), el sujeto el salón pasa de estar oscuro a estar iluminado porque las luces que posee se iluminan siguiendo una pauta establecida. Aquí no es recuperable contextualmente un agente que voluntariamente ilumina el salón: éste se ilumina gracias a un proceso que emerge de él mismo ${ }^{14}$.

21) El salón se iluminó. La exposición estaba a punto de inaugurarse. (J. P. Aparicio, Retratos de Ambigú, 1989)

Estos ejemplos son muy abundantes en nuestro corpus, debido a su fuerte motivación semántica. El prototipo de iluminar es, como vimos antes, el significado propio de la imagen esquemática SUJETO NO HUMANO PROYECTA LUZ SOBRE ALGO; la luz es incontrolable, está gobernada por pautas ajenas al C, y esto favorece que estos sujetos prototípicos que representan a entidades con luz propia (farolas, linternas, etc.) puedan incardinarse en una conceptualización inacusativa en la que se expresa cómo dichos objetos se iluminan a sí mismos, siguiendo un guión especial carente de agentes externos.

Esta última variante léxico-construccional también se emplea con frecuencia de modo metafórico, como se puede apreciar en los ejemplos (22) y (23).

22) El mendigo alzó la vista, y su rostro se iluminó de pronto con una sonrisa de bandera.

(C. Ruiz Zafón, La sombra del viento, 2001)

23) Y a la criatura se le iluminaron los ojos. (J. Maqua, Invierno sin pretexto, 1992)

Estos dos ejemplos muestran unos usos muy frecuentes de iluminar, tan frecuentes que se hallan parcialmente gramaticalizados. En este caso los sujetos sintácticos que se iluminan siguiendo un proceso interno son atributos propios de las personas, su rostro y los ojos. Estas partes del cuerpo carecen de luz en sentido estricto, pero se relacionan culturalmente con entidades abstractas como la alegría, la vida o la personalidad, conceptos todos muy positivos. El rostro del mendigo se ilumina metafóricamente en (22) porque se pone contento, y la felicidad es buena, como la LUZ; por ello, es nuevamente la metáfora LA LUZ ES

14. Como señala Mendikoetxea (1999) con los verbos inacusativos de evento de causa interna puede inferirse por conocimiento enciclopédico del mundo una fuerza o causa exterior, pero esa fuerza no está expresada lingüísticamente, puesto que lo relevante es que el proceso de cambio se inicia y culmina en el propio sujeto debido a alguna de sus peculiaridades. Por ejemplo, en $E l$ rosal floreció puede pensarse que hubo una entidad que lo regó, y que debido a ello floreció. Sin embargo, el proceso de florecer es intrínseco del rosal y se desarrolla por sí solo. Análogamente, el salón se ilumina porque tiene luces que le permiten iluminarse, con independencia de que alguien pusiera allí esas luces. 
EL BIEN la que posibilita esta variación (iluminarse pasa a significar «alegrarse»). Además, el paso de la no felicidad a la felicidad emerge en el propio sujeto y se consuma en él, razón por la cual la estructura inacusativa es la más idónea para este contenido.

El ejemplo de (23) es similar aunque en él la parte del rostro que se ilumina se concreta más al ser los ojos. Por esta razón, en este enunciado también aparece expresado el CI, la entidad proto-recipiente a quien pertenecen esos ojos (la criatura, el niño). Como comentamos antes, ya en latín lumen podía significar metafóricamente "luz de los ojos», y es esa extensión semántica la que reaparece en este ejemplo. Los ojos representan la esencia de la mirada y, por tanto, del estado de ánimo de las personas. Cuando un individuo está triste decimos que está apagado (es decir, sin luz), pero cuando está alegre se ilumina, y son los ojos, debido a su carácter simbólico, los elementos que se eligen como figura, a partir de un rostro que actuaría como fondo o marco, para expresar ese estado.

El verbo iluminar, en suma, está configurado en español como una estructura radial con un núcleo prototípico rodeado de conceptualizaciones construccionales y extensiones semánticas periféricas generadas a partir del prototipo. Dicho prototipo consiste en la imagen esquemática ENTIDAD NO HUMANA QUE PROYECTA LUZ SOBRE OTRA ENTIDAD, y su mayor prominencia viene motivada por patrones experienciales; es inusual que una entidad animada controle una luz voluntariamente, siendo lo más frecuente que la luz siga su propio movimiento. De hecho, incluso cuando sabemos por conocimiento del mundo que detrás de un proceso luminoso hay o puede haber algún agente, tendemos a expresar la percepción de ese hecho eliminando ese agente y focalizando el cambio de estado de la entidad luminosa a través de estructuras inacusativas. Por último, la LUz es una categoría cognitiva primaria la cual, gracias a diversas metáforas conceptuales, puede hacer que iluminar se deslice a dominios cognitivos relacionados con la belleza o el conocimiento. A continuación analizaremos el verbo alumbrar, para comprobar si éste posee el mismo diseño conceptual que iluminar.

\section{III.2 Alumbrar : LUZ ES ORIGEN}

El verbo alumbrar, al igual que iluminar, procede del étimo latino illumināre, por lo que podría surgir la pregunta de si pueden considerarse sinónimos. Cuando una palabra evoluciona diacrónicamente y genera dos palabras distintas, como en este caso, suele ocurrir que, o bien una de ellas desaparece (por el principio de economía lingüística que tiende a cancelar la sinonimia total entre dos términos) o bien las dos palabras coexisten desarrollando cada una matices semánticos propios. En el caso de alumbrar, y teniendo en cuenta la diferencia morfológica, nuestro análisis revela dos cosas: la primera es que este verbo no tiene una polisemia tan activa en español actual como pudiera pensarse a la 
vista de lo que dicen los diccionarios ${ }^{15}$, y la segunda es que, pese a coincidir conceptualmente con muchos aspectos de iluminar, alumbrar ha conseguido producir desarrollos propios, funcionales, como veremos a continuación.

El primer hecho que debemos resaltar es que el prototipo semántico de alumbrar es el mismo que el de iluminar, esto es, la conceptualización sUjETO NO HUMANO PROYECTA LUZ SOBRE ALGO. Los datos muestran claramente la prominencia de este valor y su altísima frecuencia de uso, exactamente como sucede con iluminar. Ese traslapo conceptual parcial entre ambos verbos se debe probablemente a su origen común y a la motivación experiencial subyacente.

El ejemplo (24) muestra un empleo de alumbrar que coincide completamente con el uso prototípico de iluminar; el C expresa que una entidad inanimada que posee luz propia (la luna) proyecta su luz sobre otra entidad que funciona como CD (la llanura) siguiendo un patrón natural, relacionado con los ciclos de los días. El hablante no interviene en el proceso y, por ello, el astro luminoso pasa a ser conceptualizado como sujeto sintáctico.

24) La noche fue igualmente larga e igualmente tensa bajo una luna que aún alumbraba con fuerza la llanura. (A. Vázquez-Figueroa, Tuareg, 1981)

Por supuesto, este significado también se utiliza metafóricamente con alumbrar. En (25) el sujeto sintáctico luminiscente la chispa de codicia es de naturaleza metafórica; el escritor recurre a esta metáfora para describir el proceso mental que experimenta un cazador en el momento de detectar una presa. El sentimiento de triunfo que le invade repentinamente cuando el hecho azaroso de que una presa potencial se presente se cumple surge porque una luz le alumbra y, por tanto, le permite ver mejor para no errar el tiro. La información que aporta la experiencia permite este uso abstracto: la luz permite hacer cosas al hacer visible el mundo y la codicia sólo se consuma haciendo ciertas cosas; por tanto, la codicia a veces emite su luz en el momento oportuno para lograr un objetivo.

25) Tras los gruesos cristales adivinaron los cofrades una chispa de codicia como la que alumbra al cazador furtivo ante la presa. (L. M. Díez Rodríguez, La fuente de la edad, 1986)

Con el resto de variantes construccionales relacionadas con la emisión de luz sucede lo mismo: los usos con sujeto humano son muy periféricos con alumbrar (tanto en un sentido físico como en un sentido metafórico), de igual modo que la aparición de un CI resulta definitivamente extraña. A continuación analizamos algunos de los pocos ejemplos encontrados:

26) Con un quinqué alumbraba la escalera primero y el pasillo después. (E. Mendoza, $L a$ verdad sobre el caso Savolta, 1975)

15. Por ejemplo, no hemos encontrado ninguna ocurrencia de alumbrar con los significados de «descubrir algo oculto bajo tierra» o "emborracharse», a pesar de que estos valores están registrados en numerosos diccionarios del español de hoy. 
27) Pudiera ahora alumbrar tantos instantes de tu vida. (F. Umbral, Mortal y rosa, 1975)

28) [...] las luces del vestíbulo le alumbraban la cara. (A. Muñoz Molina, El invierno en Lisboa, 1987)

En el ejemplo (26) tenemos una escena en la que un sujeto humano alumbra dos entidades (la escalera y el pasillo) que funcionan como CD. Al igual que ocurre en estos contextos con iluminar, aquí también está explicitado en forma de complemento instrumental el objeto con el que dicho sujeto realiza la acción (con un quinqué), y desde luego también se puede inferir una intención y una finalidad. El ejemplo de (27) pertenece a la novela en prosa poética de F. Umbral, Mortal y rosa, en la que el escritor reflexiona sobre la muerte de su hijo. En este caso el autor emplea alumbrar metafóricamente para referirse a ciertos instantes de la vida de su hijo que ahora puede recordar y recrear líricamente al poder alumbrarlos: al darles luz, esos momentos vuelven a ser visibles en una dimensión abstracta, lo que los hace nuevamente presentes y susceptibles de ser rememorados poéticamente. En cuanto al ejemplo (28), de nuevo encontramos un enunciado con sujeto no humano y $\mathrm{CI}$ en el que el beneficiario o proto-recipiente es el poseedor del CD (la cara). Aquí, las luces iluminan el rostro de forma fortuita (no intencional), y el $\mathrm{C}$ considera necesario especificar por medio del pronombre clítico le a quién pertenece dicha cara.

Hasta aquí iluminar y alumbrar se comportan exactamente igual. Ambos comparten el mismo núcleo prototípico por lo que pueden resultar prácticamente intercambiables en los contextos de uso en los que se requiere ese significado básico. Además, las variaciones léxico-construccionales producidas a partir del esquema fundamental son similares en cuanto a diseño y escasa productividad. Por lo que respecta a las extensiones y modulaciones generadas a partir de ese núcleo vamos a comprobar que, pese a haber algunas coincidencias, alumbrar ha desarrollado valores propios que no aparecen con iluminar, lo que genera una distribución complementaria entre los dos verbos.

En primer lugar, alumbrar posee con mucha frecuencia un valor léxico que, al menos nosotros, no hemos logrado documentar con iluminar; nos referimos a su uso como verbo copulativo de estado. En estos casos alumbrar significa TENER LA CAPACIDAD DE PROYECTAR LUZ, y en los ejemplos en los que aparece esta variante se conceptualiza la capacidad potencial de emitir luz que posee un sujeto no humano, razón por la cual alumbrar con este significado tiene un comportamiento intransitivo. Así, lo que se dice en el ejemplo (29) es que el sujeto la linterna ya no funciona puesto que ha desaparecido su propiedad de emitir luz. En este caso, es irrelevante si el viajero pretende alumbrar algo (un camino quizá) y lo único que expresa el verbo es la anulación eventual de la propiedad intrínseca de la linterna de proyectar luz ${ }^{16}$.

16. Por ello, un ejemplo como Esta linterna alumbra perfectamente tendría un significado netamente copulativo al expresar la noción de que funciona muy bien o, incluso, que es una excelente linterna. 
29) El viajero todavía no ha salido de La Mata y la linterna ya ha dejado de alumbrar. (J. Llamazares, El río del olvido, 1990)

Una de las extensiones semánticas que alumbrar comparte con iluminar es aquella en la que el verbo se desliza al terreno de lo epistémico. Así, encontramos usos de alumbrar en los que significa «aclarar» o "explicar». La razón de esta proyección es la misma que la que opera en el proceso con iluminar: la importancia cognitiva de la visión (y de la luz para que la visión funcione) para conocer el mundo. En (30), el sujeto Marta ha efectuado algún tipo de explicación que ha resultado decisiva para esclarecer los detalles de algún turbio asunto político, siendo el verbo alumbrar el encargado de expresar dicho esclarecimiento.

30) - Y la sobrina de nuestro primer socialista del barrio de Salamanca - añadió Marta dándole la espalda, como desentendiéndose de lo que había contribuido a alumbrar. (M. Longares, Romanticismo, 2001)

$\mathrm{Al}$ igual que sucede con iluminar, el valor epistémico que lexicaliza alumbrar tiene como fondo o marco semántico una situación previa más compleja, en la que ha sido necesario un proceso intelectual elaborado para alcanzar la cabal comprensión del hecho. En este ejemplo, ese proceso queda de manifiesto en la conversación entre los participantes, de la que la intervención de Marta no es más que el eslabón final que permite que el hecho sea alumbrado (que tenga luz metafóricamente) y, por tanto, comprendido.

A pesar de coincidir con iluminar en esta modulación semántica relacionada con el conocimiento, alumbrar posee dominios semánticos propios, vinculados con una metáfora conceptual muy peculiar que proponemos definir como LA LUZ ES EL ORIGEN. Nuestro conocimiento cultural y la influencia que la noción de la LUZ ejerce en nuestra concepción de la realidad hacen que la idea de la LUZ se relacione de modo natural con el origen de las cosas. La luz indica vida e indica existencia, puesto que sin ella no vemos, y muchas cosas no sabemos que existen hasta que las percibimos visualmente. De hecho, el imaginario antropológico sobre el nacimiento, sin ir más lejos, entiende que el niño pasa de la oscuridad a la luz exterior en el momento en el que nace, razón por la cual alumbrar (esquemáticamente PROYECTAR LUZ) ha creado el significado «dar a luz» o "parir», significado muy frecuente en el corpus y altamente gramaticalizado.

31) Si las cuitadas llegaban a alumbrar un vástago rubio [...]. (P. Faner, Flor de sal, 1986)

32) [...] recoge todas sus fuerzas para alumbrar una progenie que le enseñe a hablar. (J. Benet Gotilla, Saúl ante Samuel, 1980)

En los ejemplos (31) y (32) los CC.DD. vástago rubio y progenie representan la descendencia que unas madres van a dar a luz, proceso expresado con el verbo alumbrar. Alumbrar al hijo indica hacer que tenga luz, es decir, que su 
existencia sea evidente e incuestionable. Pero las posibilidades de la metáfora LA LUZ ES EL ORIGEN no se agotan en el significado de "parir». En otras ocasiones alumbrar se desliza hacia un campo conceptual más abstracto en el que no se conceptualiza el hacer visible lo que ya existe (hacer que el niño nazca) sino el propio proceso de creación, de producir algo que antes no existía. De este modo alumbrar también ha desarrollado, gracias a esta metáfora, el significado de «engendrar». En el ejemplo (33), la sospecha de que el juego está trucado es creada (literalmente alumbrada) en el cerebro de Juan gracias a la repetición mecánica de éste. Inicialmente todo funciona como debe, pero las sucesivas repeticiones del proceso ponen de manifiesto que algo no va bien, por lo que en la mente del observador se crea una sospecha que antes no estaba. Pues bien, la génesis de esa sospecha se expresa con el verbo alumbrar para indicar que, hasta que la luz de la inteligencia no hace visible la sospecha, ésta no existe. Alumbrar expresa aquí un valor de origen, como cuando significa "dar a luz», pero también de creación ${ }^{17}$, lo que vuelve a reafirmar la existencia de la metáfora LA LUZ ES EL ORIGEN.

33) [...] es la sistemática repetición del juego lo que en el cerebro de Juan termina por alumbrar la sospecha de que ambos sincronizan. (M. Longares, La novela del corsé, 1979)

Nuestro análisis del verbo alumbrar demuestra que este verbo comparte su prototipo semántico con iluminar; juntos cubren el dominio semántico de la proyección de la luz, en la que lo más frecuente es que el sujeto sea no humano (una fuente de luz), si bien existen otras posibilidades léxico-construccionales menos habituales. Los dos verbos comparten también su extensión hacia la expresión del conocimiento pero, más allá de esas similitudes, la estructura radial de cada uno se orienta hacia unos usos específicos. Así, alumbrar es habitualmente empleado como verbo de estado para indicar el potencial luminoso que poseen los sujetos prototípicos (linternas, lámparas, etc.), al tiempo que también posee proyecciones semánticas en las que puede expresar contenidos relacionados con el origen de las cosas, como «parir»o «engendrar», valores estos últimos de los que carece iluminar.

\section{III.3 Deslumbrar: LUZ ES FUERZA o PODER}

El verbo deslumbrar es una formación denominal creada a partir de la fusión del prefijo des- y del sustantivo lumbre. El prefijo des- procede del prefijo latino diss-, que en latín tenía dos significados, NEGACión e INTENSIDAd (Alvar \& Pottier 1983), siendo el segundo el que va a prevalecer en deslumbrar. En efecto, la idea central que vehiculan las distintas posibilidades construccionales de deslumbrar es que la Luz puede constituir una entidad muy intensa, tanto

17. Esta motivación cognitiva explica también la gramaticalización de estructuras del español como encendérsele a alguien una luz/bombilla o tener una idea luminosa, expresiones que se relacionan con la emergencia de ideas o intuiciones en el pensamiento. 
que puede alterar el estado de otra entidad que la percibe. De esa imagen básica emerge una noción de la LUZ sumamente interesante: la idea de que LA LUZ ES FUERZA o PODER. Este contenido básico conforma el prototipo de la categoría, en el que un objeto luminoso proyecta sobre una entidad animada un haz de luz tan fuerte que deja sin vista momentáneamente a esa entidad, tal y como se aprecia en la siguiente imagen esquemática ${ }^{18}$ :

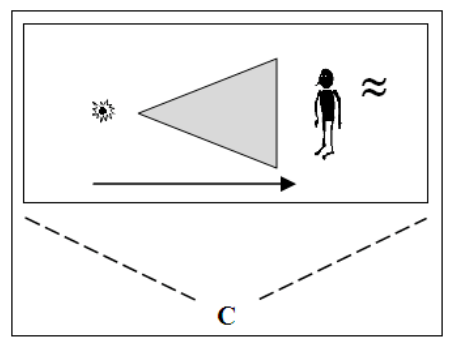

Fig. 5. - Conceptualización prototípica de deslumbrar

El análisis de los ejemplos muestra que el significado fundamental del verbo deslumbrar se halla muy influido por el contenido semántico de sus componentes morfológicos.

Deslumbrar, conceptualmente, puede tener un sujeto humano y un CD también humano. De este modo una persona proyecta luz sobre otra de tal modo que esta última experimenta una alteración transitoria en su capacidad visual. En (34), el sujeto Ambrosio proyecta una luz muy fuerte sobre otro individuo (representado por el pronombre clítico le) de modo que ésta queda sin vista. Es de notar que el CD de deslumbrar actúa, en estos casos, como un auténtico proto-paciente, puesto que su integridad se ve alterada en un sentido físico por la acción expresada por el verbo. También es frecuente con este significado que esté explicitado el complemento instrumental (con los focos) con el que el sujeto realiza la acción, ya que los sujetos humanos -al igual que ocurre con iluminar y alumbrar-carecen de luz propia (iconicidad).

34) Ambrosio, el patrón, a veces le deslumbraba con los focos y se reía. (J. M. Gironella, Los hombres lloran solos, 1987)

Otra posibilidad construccional es aquella en la que el sujeto de deslumbrar es no humano y se corresponde nuevamente con la entidad que emite la luz. En estos casos el C expresa que en la escena no hay ningún tipo de intención, tan sólo un elemento que en un momento dado ciega con su luminosidad a un CD humano. En (35) el sujeto la claridad del sol deslumbra a un hombre (CD lo) que sale a la calle. No hay voluntad, no hay agentividad: lo único que se expresa es la fuerza de esa claridad y su capacidad para cegar a una persona.

18. El símbolo $(\approx)$ que acompaña a la entidad afectada hace referencia a la alteración física que ésta experimenta en el proceso denotado por el verbo. 
35) [...] y al llegar a la calle lo deslumbra la claridad todavía veraniega del sol [...]. (A. Muñoz Molina, Sefarad. Una novela de novelas, 2001)

Esta misma conceptualización puede emplearse con un sentido metafórico. En el ejemplo (25), el sujeto sintáctico que deslumbra es una entidad abstracta, la conciencia. Nuestro conocimiento del mundo permite extrapolar metafóricamente las propiedades de un poderoso objeto luminoso capaz de deslumbrar a una entidad teórica como es la conciencia humana, de modo que la influencia de ésta en la conducta de las personas se interprete en términos de una potente luz (la de un relámpago, en el ejemplo aducido). Así, del mismo modo que una luz muy fuerte puede cegar a una persona, la conciencia también puede alterar brusca e intensamente el pensamiento de alguien, hasta cambiarlo para mejorar. Además, al relacionarse el elemento abstracto con la luz, se reviste también de un cierto halo de bondad gracias a la metáfora LA LUZ ES EL BIEN: si la luz es buena, ciertas luces muy intensas (como la de la metafórica conciencia) lo serán aún más, y representarán conceptos positivos.

36) [...] igual que la luz es más veloz que el sonido, la conciencia es más rápida que el dolor, y nos deslumbra como un relámpago que sucede en silencio. (A. Muñoz Molina, El invierno en Lisboa, 1998)

El esquema experiencial comentado se ha proyectado en el caso del verbo deslumbrar a un dominio metafórico manteniendo intacta su estructura, lo que ha posibilitado que este verbo haya lexicalizado un significado muy importante dentro de su red semántica: nos referimos al significado de «impresionar». Una entidad luminosa puede ser tan intensa que una entidad receptora quede alterada por ella, y en un plano figurado una entidad humana puede tener una determinada propiedad tan interesante o llamativa que consiga generar un estado de conciencia nuevo en sus receptores. Con este significado se pierde en la proyección la idea de una afectación física ${ }^{19}$ para quedar sólo un estado cognitivo nuevo, un cambio en la apreciación que el CD humano tiene del sujeto $^{20}$. Normalmente este significado se utiliza en contextos en los que el sujeto llama la atención por alguna cualidad positiva o inusual. Veamos algunos ejemplos:

37) Que, no obstante su natural sencillez, cuando el protocolo de la Corte lo aconsejaba, sabía deslumbrar a nobles y plebeyos luciendo los más suntuosos trajes y las joyas más valiosas. (F. Vizcaíno Casas, Isabel, camisa vieja, 1992)

19. No obstante, resulta interesante resaltar que el sustantivo impresión procede del latín impressio, que significaba, entre otras cosas, "marca», "choque de un enemigo" o "ataque». Por tanto, incluso impresión o el verbo derivado impresionar proceden diacrónicamente de un sustantivo que expresaba alteración física, significado que se gramaticalizó en su desarrollo en español. Por ello no es nada extraño que deslumbrar haya podido generar el contenido de «impresionar» a partir de un prototipo vinculado a la alteración física.

20. Para una interesante reflexión sobre la relación cognitiva entre la percepción y los estados mentales véase Croft (1993). 
38) Con aquellas frases que le habían repartido no iba a poder deslumbrar a los del cine, ni exhibir sus dotes de actor, que no eran pocas [...]. (F. Fernán Gómez, El viaje a ninguna parte, 1995)

En estos dos ejemplos hallamos unos sujetos sintácticos (elididos) que causan una profunda impresión a unos individuos (nobles y plebeyos y a los del cine) que funcionan como proto-pacientes, cuya valoración de los sujetos va a cambiar tras conocerlos. No obstante, la razón por la que esos sujetos van a impresionarlos es distinta en cada caso. En (37) el sujeto femenino logra deslumbrar por llevar trajes y joyas hermosos; esos elementos reforzarán su imagen externa y, en un contexto determinado, causarán por sí solos el efecto transformador. En cambio, en (38) el atributo que puede permitir que el sujeto cause una impresión efectiva en sus observadores es más abstracto, puesto que se relaciona con su talento para la actuación dramática. Si en el ejemplo anterior unas joyas podían bastar para deslumbrar a los presentes en la fiesta, en éste se requieren frases teatrales de calidad para que el talento del actor pueda manifestarse y ser adecuadamente percibido y valorado.

En ocasiones con este esquema el $\mathrm{C}$ puede considerar irrelevante la presencia del $\mathrm{CD}$. Cuando esto sucede el verbo sigue significando «impresionar», sólo que la escena está conceptualizada de un modo diferente, como se aprecia en el ejemplo (39). Como vemos, aquí no aparece en escena ningún $\mathrm{CD}$ humano, el cual existe necesariamente (la acción de impresionar sólo se consuma en el receptor), sólo que queda en un segundo plano, en el marco de la conceptualización. Así, se perfila y da prominencia conceptual al deseo del sujeto de destacar, de ser el mejor en los exámenes.

39) Los exámenes se aproximaban y Edmundo los preparó a conciencia. Necesitaba deslumbrar para que le fuera perdonado su error con el hombre del jersey azul. (B. Gopegui, Lo real, 2001)

Como resulta evidente, deslumbrar es un verbo netamente causativo puesto que expresa una predicación de la que emana un flujo de energía que será causa de que un elemento externo cambie. Lo interesante es que con el significado de «impresionar» encontramos numerosos ejemplos pasivos con la estructura dejarse + deslumbrar que conceptualizan el deseo consciente (o al menos la predisposición) del proto-paciente -que funciona en estos casos como sujeto sintáctico- para cambiar, para quedar impresionado. Se trata de estructuras sumamente interesantes en las que el proto-paciente adopta una actitud parcialmente activa, como si tuviera una inclinación natural a recibir dicha impresión. Por ello, en este caso, aparece el verbo dejar el cual expresa metafóricamente la PERMIsión causativa, la eliminación de cualquier barrera que impida que el evento alcance su desarrollo: el sujeto quiere quedar impresionado y dicho deseo es liberado.

En (40), el sujeto el pueblo (metonimia que representa a una gran masa de gente) tiene una actitud receptiva para ser deslumbrado por su héroe. Esa falta de resistencia del pueblo hace que se represente la escena en voz pasiva, con 
un paciente como sujeto que no ejerce contrafuerza al cambio, y un agente en forma de complemento (por tu aureola) que expresa la esencia positiva de la que procede la belleza y autoridad que el pueblo ansía.

40) Si entras en Roma ostentando como un triunfo la victoria sobre los partos, el pueblo se dejará deslumbrar por tu aureola. (T. Moix, No digas que fue un sueño, 1993)

No obstante, también existen casos en los que el sujeto, consciente de que un estímulo va a llegarle con la intención de impresionarle hasta cambiar su opinión o estado mental, ejerce una fuerza de oposición para impedirlo, por lo que la estructura se niega, como en (41). El sujeto sintáctico Pepe tiene muy presente que los tres individuos que le acompañan podrían arrebatarle su posición. Ese convencimiento procede de hechos concretos de la situación contextual (tal vez los otros tres tengan mayor fortaleza física), hechos que podrían impresionarlo en determinadas circunstancias. Sin embargo el sujeto resiste y bloquea ese potencial cambio de estado en su comportamiento.

41) Pepe los reclamó al salón, donde presidía con su pistola. Él controlaba por los tres y no se dejaba deslumbrar tan fácilmente. (J. L. Martín Vigil, En defensa propia, 1985)

Para terminar, deslumbrar, al igual que alumbrar, puede expresar, con sujetos no humanos, un estado intransitivo, la capacidad de una fuente de luz de emitir una luminosidad intensísima capaz de cegar. En (42) se enuncia que el sujeto $e l$ fulgor posee un brillo intenso que puede deslumbrar, por lo que se trata de una estructura copulativa que sólo representa una propiedad o atributo intrínseco de la fuente de luz.

42) Al fondo, la caja fuerte abierta, donde titila una montañita de brillantes, el fulgor que deslumbra. (J. Ribera, La sangre de mi hermano, 1988)

El verbo deslumbrar no posee tantas variantes léxico-construccionales como iluminar o alumbrar, ni ha desarrollado muchos significados abstractos, pero aun así es un verbo muy interesante por el hecho de que codifica múltiples variaciones relacionadas con la metáfora LA LUZ ES FUERZA. Como hemos comprobado, el conocimiento de la luz que tienen los hablantes no sólo se relaciona con su potencial para permitir la visión, con lo que ello implica, o con su naturaleza incontrolable, sino que también tiene que ver con hechos como que hay fuentes de luz muy intensas. De ese bagaje sensorial saldrá la estructura esquemática en que se apoyan las distintas conceptualizaciones de deslumbrar.

\section{III.4 Vislumbrar: LUZ ES FUGACIDAD}

Vislumbrar es un compuesto formado con la fusión del adverbio latino de negación uix, que significaba «apenas» $\mathrm{o}$ «con dificultad», y el verbo illumināre, ya comentado (Corominas \& Pascual 1980-1991). Se obtiene así un verbo 
nuevo cuyo significado prototípico está fuertemente influido por la semántica que imponen sus constituyentes, como le ocurre a deslumbrar. Así, vislumbrar lexicaliza la DIFICULTAD PARA LA VISIÓn, puesto que el adverbio uix matiza que la LUZ, conceptualmente, es escasa, por lo que la percepción visual se halla condicionada, negativamente, por este hecho.

El verbo vislumbrar es un verbo de percepción visual. En su marco semántico aparecen los dos elementos fundamentales que caracterizan a estos verbos, puesto que por un lado hay un perceptor, que es quien percibe por la vista, y por otro hay un percepto, el estímulo visual que puede percibirse. Lo más llamativo es que, dentro del espectro de posibilidades léxico-construccionales que este esquema básico tiene en español ${ }^{21}$, vislumbrar está especializado en la conceptualización de la dificultad para que el percepto sea percibido. De este modo, la escena está configurada de manera que la distancia espacial que hay entre esos dos elementos está llena de obstáculos o impedimentos que hacen que la visión resulte problemática. En otras ocasiones, será la propia naturaleza del percepto (su fugacidad, su intermitencia, su transparencia, etc.) la causa de que sea difícil verlo. Por todo ello, el prototipo de vislumbrar se corresponde con el esquema «PERCEPTOR (habitualmente humano) más PERCEPTO FÍsICO (una entidad visible) en un marco contextual de dificultad para la visión», tal y como mostramos en la siguiente idealización esquemática ${ }^{22}$ :

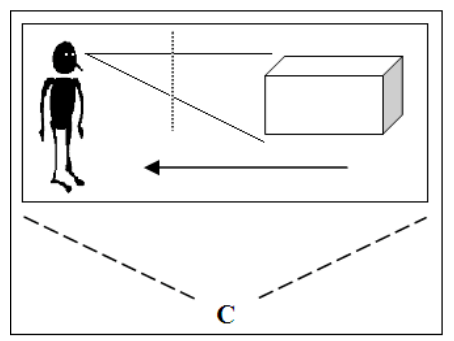

Fig. 6. - Conceptualización prototípica de vislumbrar

En los ejemplos siguientes encontramos siempre indicios contextuales que señalan que el entorno o la esencia del percepto le dificultan la visión al perceptor, en mayor o menor grado.

43) Relacionó sus rodillas, bailando como enloquecidas aspas de molino, con las sombras que alcanzaba a vislumbrar sobre una pequeña alfombra, sobre su vista. (F. J. Satué, La carne, 1991)

21. Para un detallado análisis de las propiedades construccionales y conceptuales de los principales verbos de percepción visual del español llevado a cabo mediante el análisis de corpus véase Hanegreefs (2008).

22. La línea vertical puntuada simboliza las dificultades que pragmáticamente suelen aparecer en la escena, mientras que la flecha señala la orientación básica del flujo de energía, del percepto al perceptor (ausencia de control perceptivo). 
44) Vislumbró el vuelo fugaz de un pájaro. (F. Hernández, La certeza, 1989)

45) Se acercó y a través de las hojas ligeramente oscilantes vislumbró la hendidura en la roca. (F. Hernández, Naturaleza, 1989)

46) Desde este sitio - continuó- puedo vislumbrar el firmamento sin alzar la vista. (F. Hernández, Naturaleza, 1989)

En el ejemplo (43) el percepto las sombras es, tanto por su naturaleza inasible como por el contexto pragmático, difícil de percibir. Por ello el C utiliza la perífrasis verbal alcanzar a + infinitivo (siendo vislumbrar el verbo auxiliado) para indicar que sólo tras un esfuerzo voluntario, dadas las dificultades contextuales, se logra la culminación de la percepción visual de esas sombras. En (44) el adjetivo fugaz que acompaña al núcleo del CD vuelo denota que el percepto resulta efímero y, por ello, de problemática captación. Por su parte, en el ejemplo (45) el perceptor sólo logra ver el percepto (la hendidura en la roca) tras acercarse a éste, cubriendo la distancia que los separa, percepción que también se ve afectada por la existencia de una barrera física entre ambos, unas hojas ligeramente oscilantes; por ello, tanto por la distancia como por unas hojas que enturbian la percepción, el $\mathrm{C}$ ha optado por emplear vislumbrar, y no otro verbo como ver u observar. Por último, en (46) la percepción es un poco más factible que en el resto de casos, e incluso el circunstancial sin alzar la vista parece indicar que el perceptor adopta una actitud pasiva. No obstante, el sintagma desde este sitio indica que hay una notable distancia que, en otras circunstancias, podría hacer problemática la visión del firmamento. De este modo, en el ejemplo (46), los elementos de dificultad quedan sólo en el marco de la escena como fondo conceptual no perfilado.

El significado prototípico de vislumbrar que acabamos de analizar también puede proyectarse a un plano más abstracto para fusionarse con el significado epistémico ya comentado que caracteriza con frecuencia a los verbos relacionados con la luz y la visión. Vislumbrar puede, efectivamente, expresar contenidos epistémicos, si bien con este verbo la información modal nos dice que el conocimiento que el perceptor obtiene resulta incipiente o incompleto, debido a que el percepto sigue manteniendo la idea de fugacidad o imprecisión. Por supuesto, el contexto vuelve a indicar que la obtención de ese conocimiento exige superar una serie de trabas previas. Observemos dos ejemplos:

47) Escruto el semblante de la mujer vislumbrando en el fruncimiento de las cejas pintadas un punto de malicia. (F. J. Satué, La carne, 1991)

48) Entre los horrores de nuestro tiempo, Lamo de Espinosa vislumbra el triunfo del orden liberal democrático-universal. (J. Benet Goitia, Saúl ante Samuel, 1980)

El ejemplo (47) nos muestra un perceptor en primera persona (elidido) que logra conocer o barruntar un percepto abstracto (un punto de malicia). La intuición de la malicia de la mujer sólo se alcanza tras un intenso esfuerzo, representado en la escena por el verbo escrutar, que indica una percepción visual 
concentrada y prolongada que pretende descubrir una realidad no evidente ${ }^{23}$ : el perceptor observa durante largo rato el rostro de la mujer, y sólo tras ese proceso alcanza el logro epistémico (determinar que es maliciosa). El conocimiento que se expresa en (48) es más contingente que el de (47). En este caso el perceptor Lamo de Espinosa intuye un percepto vinculado a una información política, el triunfo del orden liberal democrático-universal. La dificultad para llegar a ese estado de conocimiento se debe en este caso a la intrínseca subjetividad que caracteriza al mundo de la vida pública. El Modelo Cognitivo Idealizado (MCI) de política incluye por defecto la disensión, el desacuerdo, el punto de vista individual, y por ello el escritor ha utilizado vislumbrar, para señalar que esa idea que el sujeto dice haber alcanzado gracias a la observación de los hechos no se puede entender en términos absolutos, sino sólo como una apreciación personal.

El verbo vislumbrar también puede funcionar de acuerdo con lo que se ha denominado percepción valorativa (Hanegreefs 2008). La percepción valorativa es aquella en la que el verbo no expresa en sentido estricto una visión real de un fenómeno del mundo, sino que es una percepción que procede del intelecto y de la subjetividad del perceptor, en la que se enuncia un juicio de valor sobre un hecho de la realidad ${ }^{24}$. En este caso, vislumbrar se comporta como un verbo de actitud proposicional, como considerar, juzgar u opinar. La estructura sintáctica con percepción valorativa es, potencialmente, muy variada, puesto que en realidad es el contexto el que suele indicar que en ese caso lo que el sujeto expresa no es una percepción sino una enunciación fuertemente modalizada. Aun así, hay conceptualizaciones que hacen que la estructura se vuelva valorativa automáticamente al imposibilitar una lectura meramente visual. Una de esas estructuras es la que responde a la fórmula «PERCEPTOR (humano) + PERCEPTO (concreto o abstracto) + C. PREDICATIVO»:

49) En efecto, La conexión Bellarrosa incluye, apenas si esbozada, materia argumental como para una novela extensa que vislumbramos fascinante. (ABC Cultural, 20/12/1991)

50) No quiso pensar en el cansancio. Podía vislumbrar la sensación como una amenaza expresada mediante una fórmula críptica. (F. J. Satué, La carne, 1991)

23. Para un profundo análisis de las propiedades del verbo escrutar y de sus diferencias con escudriñar véase el trabajo de Delbecque \& Hanegreefs (2006).

24. Es necesario diferenciar entre percepción cognitiva y percepción valorativa. La percepción cognitiva, representada fundamentalmente por los casos en que un verbo de percepción visual o auditiva va complementado por una oración completiva, indica comprensión o constatación de un hecho, a partir de una observación directa de la realidad. Por ejemplo, en la oración Veo que has comprado un coche nuevo el perceptor ve unos acontecimientos concretos (a su vecino en un vehículo diferente del habitual, etc.) y, siguiendo un razonamiento basado en la lógica que regula el mundo, enuncia con ver su comprensión cognitiva de ese hecho. Sin embargo, la percepción valorativa es más abstracta y más subjetiva; en ella no es necesario que el perceptor siga las reglas lógicas de la realidad y, de hecho, ni siquiera es imprescindible que su afirmación se base en circunstancias que se puedan ver. La percepción valorativa es puramente individual y axiológica, y, por ello, en la escena suelen aparecer sintagmas atributivos que enmarcan la evaluación que lleva a cabo el sujeto. Para un detallado análisis de estas estructuras véanse los trabajos de Rodríguez Espiñeira (2000) y Hanegreefs (2008). 
En el ejemplo (49) el crítico literario concluye su reflexión emitiendo una observación final sobre una novela que podría escribirse. Dicha novela aún no existe, pero el crítico imagina subjetivamente que, de existir, seguramente sería fascinante. Este adjetivo, que funciona como complemento predicativo orientado al CD novela extensa, codifica inequívocamente el punto de vista particular que el sujeto tiene de dicha novela. El percepto no es, pues, un objeto visible sino sólo un metafenómeno creado en la imaginación del perceptor y valorado por él, valoración codificada por el predicativo. Además, vislumbrar sigue manteniendo su marco de DIFICULTAD PARA VER, puesto que es más difícil valorar un objeto que no existe (la novela extensa) que otro que es tangible.

El ejemplo (50) es similar. Tenemos un sujeto que juzga su sensación (de cansancio), empleando vislumbrar. En este caso, el elemento atributivo que especifica cómo siente interiormente el perceptor ese percepto viene representado por una construcción comparativa introducida por el nexo modal como (como una amenaza expresada mediante una fórmula críptica). Al comparar la sensación de cansancio con una entidad puramente metafórica (la amenaza) se está indicando que la visión en este caso no actúa; todo se reduce a un proceso cognitivo de evaluación.

Finalmente, vislumbrar también aparece en estructuras copulativas en las que, como ya explicamos, el percepto se conceptualiza como sujeto sintáctico. De este modo el C realza la presencia del estímulo que puede vislumbrarse y le otorga mayor prominencia en la escena. Los datos muestran que en estas estructuras vislumbrar suele tener un significado metafórico o epistémico, lo cual es sumamente interesante; cuando la estructura copulativa se relaciona con una percepción visual física el hablante prefiere emplear el verbo ver, que es el más general y neutro en el conjunto de los verbos de percepción del español. Sin embargo, con vislumbrar la estructura se emplea para fines discursivos más elaborados, en los que se pretende conceder protagonismo a una entidad más o menos nocional que emerge en la escena en un momento dado, como se aprecia a continuación:

51) La televisión seguía sin llegar a todos los hogares y, aunque el color ya se empezaba a vislumbrar, la mayoría aún seguía inmersa en el blanco y el negro. (El Norte de Castilla, $15 / 06 / 2002)$

52) Tras once años, ya comienzan a vislumbrarse los frutos de tan ardua labor. (ABC Cultural, $12 / 07 / 1996)$

53) Y lo peor es que no se vislumbra una solución de estabilidad. (El Mundo, 19/02/1994)

No deja de ser llamativo que en muchos casos, como en estos ejemplos, esta variante léxico-construccional de vislumbrar aparezca en artículos periodísticos, el género relacionado con la actualidad ${ }^{25}$. En ese contexto vislumbrar ofrece un excelente patrón conceptual para explicar la llegada de una entidad nueva, más o menos súbita. Así, los sujetos sintácticos el color, los frutos de tan ardua labor y una solución de estabilidad son entidades que se presentan en su determinado

25. De hecho, como se aprecia en la Tabla 1, del total de 104 ocurrencias documentadas de vislumbrar, 44 pertenecen a textos de prensa, lo que supone un 45,76\% del total. 
contexto cuando se dan unas determinadas condiciones, relacionadas con los acuerdos políticos, con trabajo prolongado o con años de ahorro para poder comprar una televisión de color. De nuevo, la visión y la luz se relacionan con la CREACIÓN; la visión física de un objeto pasaría, en el marco de vislumbrar, por tres fases: AUSENCIA DE VISIÓN > VISIÓN INTERMITENTE > VISIÓN TOTAL.

Análogamente, en un plano abstracto, un acuerdo, o algo extraño en cierto momento de la historia como los televisores de color, en momentos iniciales del proceso pragmático no se verían en absoluto (aún no existen), después, en una segunda fase de debates políticos o de ahorro familiar, empezarían a gestarse gradualmente y, por último, si el proceso es exitoso, la entidad podría verse por completo (ya existe). Pues bien, este marco esquemático en una conceptualización copulativa focaliza las fases finales del proceso, es decir, la gestación y potencial llegada de la entidad nueva. El C quiere resaltar ese proceso de desarrollo y por ello opta por una configuración conceptual en la que el elemento emergente es el sujeto sintáctico. Con todo, el uso de vislumbrar actualiza en la mente del hablante el marco conceptual completo, con lo que la cohesión semántica del texto es total.

El estudio de vislumbrar permite reafirmar la trascendencia que la LUZ como categoría cognitiva tiene en el pensamiento humano. Si ésta existe, existen las demás cosas, existe el conocimiento, etc. Si es esporádica, como lexicaliza vislumbrar, la visión se resiente y, por ello, todos los significados proyectados del prototipo materializan esa dificultad visual. Aun así, como hemos comprobado, este verbo resulta enormemente productivo en contextos como los artículos de prensa o de crítica política, puesto que su peculiar configuración permite expresar el logro de acuerdos o la llegada de noticias de un modo eficaz en ese plano discursivo.

\section{III.5 Columbrar: LUZ ES REVELACIÓN}

El último de nuestros verbos es el que posee una etimología más problemática. La teoría más extendida entiende que columbrar procede, tal vez por una modificación fonética reforzada por la presencia de vislumbrar, de una hipotética forma latina * culmbrar, generada a su vez en culminare, derivado de culmen, que significaba en latín «cumbre» o "altura» (Corominas \& Pascual 1980-1991). El significado de este verbo, según ese origen, sería «ver desde lejos». El hecho incuestionable que muestran los datos es que columbrar significa prototípicamente en español actual «ver»o «descubrir». Es, pues, un verbo de percepción visual que, o bien expresa una visión que se alcanza sin dificultades tras cubrir una cierta distancia hasta el percepto, o bien expresa la noción epistémica del descubrimiento al verse de forma azarosa una entidad. Para el desarrollo conceptual de ambos significados resulta decisiva la idea de LEJANía (que no obstáculo insalvable) existente entre perceptor y percepto 
que la etimología impone. La imagen mental que activa columbrar puede representarse como sigue ${ }^{26}$ :

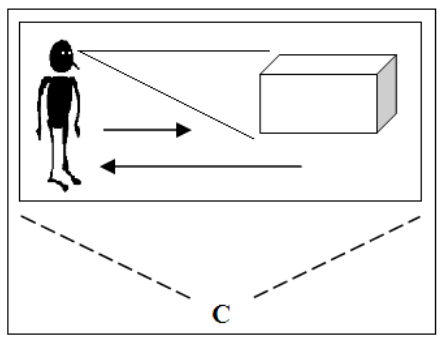

Fig. 7. - Conceptualización prototípica de columbrar

En los contextos siguientes (54-57) la acción visual es resultativa, es decir, se produce automáticamente en cuanto el perceptor ve el percepto. No obstante, del contexto se desprenden marcas que remiten a una distancia física (de mayor o menor longitud) que ha habido que cubrir hasta llegar al percepto.

54) Y una vez que sus pupilas columbraron los nombres en la lista, deletreó en voz baja, ansiosamente, los incluidos en la letra C... (M. Delibes, Madera de héroe, 1987)

55) [...] cuando alcancen la cima lo columbrarán en lontananza. (La Vanguardia, 27/02/1994)

56) Y algo más iba a añadir cuando la columbraron por detrás de unas chumberas en compañía de una vieja bruja. (J. M. Caballero Bonald, Toda la noche oyeron pasar pájaros, 1981)

57) Abrió don Fermín el ojo menos castigado por la solera y columbró lo que parecía ser una visión provocada por el exceso de solera [...]. (J. M. Caballero Bonald, Toda la noche oyeron pasar pájaros, 1981)

En (54) podemos imaginar a los sujetos acercándose lo más posible a la lista para poder ver los nombres (CD). El ejemplo de (55) expresa claramente que la visión de un determinado objeto (representado por el clítico lo) sólo es posible tras alcanzar la cima, por lo que existe hasta esa visión una notable distancia que hay que recorrer. En cuanto al ejemplo (56), en él columbrar se desliza al significado de "descubrir»: cuando se deambula por un lugar cabe la posibilidad de que determinadas realidades se encuentren allí y sean vistas inesperadamente (idea de descubrimiento involuntario). Es lo que ocurre en este caso, ya que unos sujetos descubren a una persona de modo errático al pasar por un determinado escenario, siendo ese descubrimiento tan inesperado que la conversación que mantenían los sujetos se interrumpe. Finalmente, (57) constituye un ejemplo un poco más infraespecificado, conceptualizado como un logro aspectual instantáneo. El sujeto Don Fermín columbra una

26. En este caso las flechas de orientación contrapuesta indican tanto el sentido de la marcha del perceptor como la distancia que separa a perceptor y percepto. 
entidad abstracta, introducida por un CD en forma de cláusula de relativo sin antecedente expreso, sólo por el hecho de abrir el ojo. En este caso la idea de DISTANCIA no se perfila, por lo que columbrar se superpone conceptualmente a ver.

De esto último se desprende que columbrar en numerosos contextos puede cancelar su imagen original de DisTANCia para focalizar el logro visual. Por ello no resulta extraño que este verbo pueda ir complementado fácilmente por perceptos abstractos en contextos epistémicos. Cuando esto ocurre, columbrar desarrolla significados como "comprender» o "percatarse de algo", significados que también posee con frecuencia ver:

58) Tampoco podía columbrar que Villamuera andaba por los despachos buscándole. (A. Rojo, Matar para vivir, 2002)

59) [...] tras haber mordido la fruta 131 Génesis 3.6. ha columbrado la superchería de la prohibición [...]. (J. Benet Goitia, Saúl ante Samuel, 1980)

En el ejemplo (58) columbrar significa claramente «comprender». El sujeto en tercera persona está siendo buscado insistentemente por Villamuera, hecho que dicho sujeto no puede explicar. Así, el verbo columbrar, al ir negado, denota que una determinada realidad del mundo, codificada en forma de oración subordinada completiva en función de CD (que Villamuera andaba por los despachos buscándole) no es comprendida por su perceptor. La frase (59) tiene como objeto un sustantivo abstracto relacionado con una falsa creencia (una superchería), por lo que la lectura semántica se desliza al terreno del conocimiento de forma inmediata.

Por último, columbrar también puede funcionar como verbo copulativo con un sujeto que representa al percepto, tanto en un sentido puramente visual como en un dominio metafórico. El ejemplo (60) muestra a una entidad en función de sujeto (el rostro de un hombre) que se revela tras unos elementos superficiales (una barba y un bigote) que actúan de barrera. La idea sugerida es la de una aparición repentina, sorpresiva, que alcanza al perceptor de forma incontrolada, y gracias a la cual una entidad se muestra para poder ser conocida. En (61) la conceptualización se mantiene, sólo que opera en un marco metafórico. Lo que aquí se va revelando gradualmente gracias a la tenue luz de una vela es un conjunto de miedos, el cual aflora poco a poco en la conciencia del perceptor. Esos miedos van llegando progresivamente (paso de la no existencia a la existencia), idea, una vez más, reforzada por el concepto subyacente de la LUZ y por la conceptualización copulativa que ubica en primer plano al propio miedo.

60) Tras la barba y el bigote negros, se columbraba el rostro de un hombre que apenas sobrepasaba los treinta ańos. (T. Luca de Tena, Los renglones torcidos de Dios, 1979)

61) A Lorenzo empezó a producirle un más mortificante escalofrío la húmeda bocanada de la oscuridad, esa rotación quimérica de bultos impulsados por la llamita del candil, entre los que no tardaría en columbrarse la imposible calavera de todos los peligros de muerte o la imaginaria sombra de Jaquemate. (J. M. Caballero Bonald, Toda la noche oyeron pasar pájaros, 1981) 
Como vemos, la idea nuclear que caracteriza a columbrar en todas sus variantes es la de una REVELACión IMPUlSAdA POR EL PERCEPTO. Tanto cuando el hablante ve algo por cubrir una distancia, como cuando lo descubre inesperadamente o se manifiesta de forma incontrolada (variante copulativa) es el estímulo el que se muestra al observador, quien tan sólo lo registra. La luz natural nos permite ver el entorno, y columbrar se encarga de expresar cómo esa luz puede a veces llegar con toda naturalidad a los hablantes para ir mostrándoles diferentes facetas del mundo, tanto físicas como abstractas.

\section{Conclusiones}

Como hemos ido comprobando a lo largo de estas páginas, la idea de la LUZ resulta decisiva en la experiencia humana. Las personas necesitan la luz para ver el mundo, puesto que los ojos del Homo sapiens no pueden ver sin ella. Consecuentemente, este concepto conecta de modo natural con facetas de la vida como la supervivencia, la seguridad o la belleza, extensión metonímica motivada por la apreciación positiva que el hombre tiene de la luz. Asimismo, nuestros sentidos registran cómo es el comportamiento físico de esta evanescente entidad; la luz es escurridiza, aleatoria, intermitente, en suma, constituye una categoría activa, que los humanos han podido controlar sólo muy puntualmente a lo largo de la evolución.

Todo este bagaje experiencial forma el marco conceptual que permite la gramaticalización de múltiples unidades verbales relacionadas con este dominio semántico. En nuestro estudio nos hemos centrado en cinco verbos que, debido a su origen etimológico, están directamente vinculados con la noción de la LUz. Si bien se trata de verbos de un nivel léxico subordinado (esto es, más concreto que otros verbos más generales de la categoría como ver) los cuales comparten, además, muchas propiedades, lo cierto es que nuestra investigación prueba que no son unidades sinónimas. No obstante, sí es cierto que su relación con un dominio prácticamente universal como es la idea de la visión (posibilitada por la LUz) hace que haya algunas zonas conceptuales compartidas, como la facilidad de casi todos estos verbos para expresar la posesión de conocimiento.

Aun así, más allá de lo que puedan compartir, cada uno de estos verbos conceptualiza aspectos particulares de la experiencia que se puede tener con la Luz. Iluminar es capaz de representar la idea de la belleza procedente de la posesión de luz de una entidad, por lo que en su estructura aparece la metáfora LUZ ES BELLEZA. Alumbrar se orienta más a la concepción de la luz como entidad creadora en la metáfora LA LUZ ES EL ORIGEN. Deslumbrar resalta la capacidad de cegar de las luces intensas, lo que supone una forma de modificar a otras entidades: LA LUZ ES PODER. Por su parte, vislumbrar ha generado la metáfora conceptual LA LUZ ES FUGACIDAD para indicar que, en ocasiones, la visión de las cosas se halla condicionada por factores azarosos, relacionados con el contexto o con el propio objeto visual. Finalmente, columbrar muestra que LA LUZ ES REVELACIÓN, surgimiento evidente ante los ojos de los observadores. Toda esta 
constelación de matices muestra, por un lado, la riqueza semántica de la LUz como primitivo preconceptual, $y$, por otro, cómo estos verbos existen porque son capaces de expresar contenidos específicos (ausencia de sinonimia).

Otro hecho destacable es que el funcionamiento léxico-construccional de nuestros verbos encaja en un continuo gradual con dos polos opuestos, uno relacionado con la causatividad y otro con la percepción visual, tal y como se aprecia en la siguiente figura:

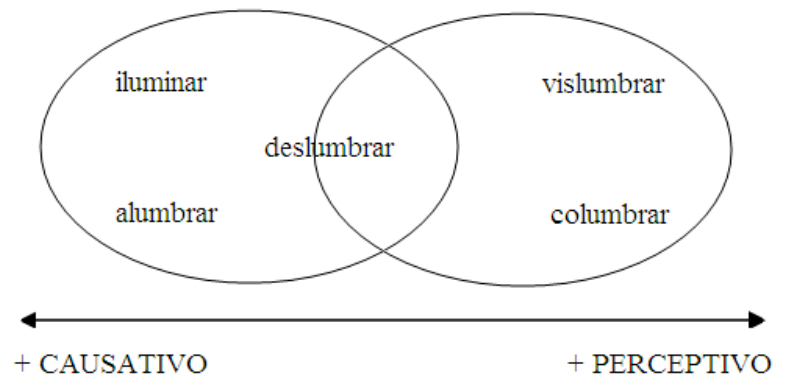

Fig. 8. - Continuo gradual entre causatividad y percepción visual

El extremo causativo está representado por iluminar y alumbrar. Ambos verbos materializan acciones capaces de alterar las propiedades de un objeto, y se pueden descomponer en la perífrasis analítica PROYECTAR LUZ SOBRE ALGO. En ambos casos el $\mathrm{C}$ concibe una escena definida por su deixis epistémica u objetiva (es decir, con una mínima presencia de subjetividad), al resaltar prototípicamente la existencia de las fuente de luz (los sujetos sintácticos), dejando en un segundo plano cualquier elemento que indique intencionalidad, incluidos los CC.II., que resultan absolutamente periféricos en la situación descrita.

En el otro extremo encontramos los verbos de percepción visual vislumbrar y columbrar, los cuales se caracterizan por un esquema binario formado por un PERCEPTOR y un PERCEPTO en el que está excluida por completo la presencia de un beneficiario en forma de CI; este esquema sufre diferentes estructuraciones construccionales en función de cómo quiera presentar la escena el $\mathrm{C}$, y en él lo prototípico es la presencia de perceptores humanos y de perceptos muy variados, que van desde entidades inanimadas y visibles, hasta conceptos abstractos o contenidos proposicionales. Con frecuencia, como también hemos podido constatar, la construcción sintáctica reproduce de diversos modos todos los elementos de dificultad, distancia o evaluación modal que completan el significado de la escena.

En cuanto al verbo deslumbrar, éste es quizá el más peculiar de los cinco. Por un lado, se relaciona con iluminar y alumbrar por ser un verbo causativo, por tener prototípicamente sujETOS NO HUMANOS (fuentes de luz) y porque el CI con él, no siendo imposible, sí es muy raro. Además, es junto con alumbrar el que más fácilmente expresa la idea de estado y capacidad, posibilidad que con 
iluminar, aunque puede existir, resulta mucho más inusual (ningún ejemplo en el corpus analizado). No obstante, deslumbrar se relaciona conceptualmente con la visión con mayor claridad que iluminar y alumbrar, puesto que expresa alteraciones de la vista por el exceso de luz, razón por la cual lo situamos ligeramente hacia la derecha en el continuo que hemos propuesto.

En definitiva, pensamos que nuestro trabajo permite validar en términos generales las teorías fundamentales de la LC. La experiencia (tanto corporal como cultural) juega un papel decisivo en el diseño lingüístico, lo que indica que el uso es el motor de la lexicalización de conceptos. En nuestro caso, ha sido el campo de la Luz, expresado en cinco verbos diferentes, el que nos ha permitido comprobar que las categorías forman redes conceptuales superpuestas con núcleo prototípico y elementos periféricos, y que esa configuración tiene una motivación pragmática que pauta icónicamente la estructuración léxicoconstruccional.

\section{REFERENCIAS}

Achard Michel, Representation of cognitive structures. Syntax and semantics of French sentential complements, Berlin/New York, Mouton de Gruyter, 1998.

Alvar Manuel \& Pottier Bernard, Morfología histórica del español, Madrid, Gredos, 1983.

Ballester Xaverio, «Hablar a primera vista», Quaderns de Filologia. Estudis Lingüistics, 2009, XIV, 13-31.

Bat-Zeev Shyldkrot Hava, «Les verbes de perception: étude sémantique», en Kremer Dieter (ed.): Actes du XVII Congrès International de Linguistique et Philologie Romanes, Tome IV, Université de Trèves, Tübingen, Max Niemeyer Verlag, 1989, p. 282-294.

Bolinger Dwight, «Concept and percept: two infinitive constructions and their vicissitudes», en Onishi Masao (ed.), World papers in phonetics: festschrift for Dr. Onishis Kizyu, Tokyo, Phonetic Society of Japan, 1974, p. 65-91.

Brugman Claudia \& Lakoff George, "Cognitive topology and lexical networks», en Small Steven, Cottrell Garrison \& Tanenhaus Michael (eds.), Lexical ambiguity resolution, San Mateo, CA: Morgan Kaufman, 1988, p. 477-507.

Corominas Joan \& Pascual José A., Diccionario crítico etimológico castellano e hispánico, Madrid: Gredos, 1980-1991.

Croft William, "Case marking and the semantics of mental verbs», en Pustejovsky James (ed.), Semantics and the Lexicon, Dordrecht, Kluwer, 1993, p. 55-72.

Croft William \& Cruse Alan D., Cognitive Linguistics, Cambridge, Cambridge University Press, 2004.

Cuartero Otal Juan, "Cosas que se hacen. Esquemas sintáctico-semánticos agentivos del español», en Wotjak Gerd (ed.), Studien Zur Romanischen Sprachwissenschaft Und Interkulturellen Kommunikation 11, Frankfurt am Main, Peter Lang, 2003.

Cuenca María Josep \& Hilferty Joseph, Introducción a la lingüistica española, Barcelona, Ariel, 1999.

Danesi Marcel, «The metaphorical extension of vision: a linguistic universal?», Geolinguistics, 1985, II, p. 1-12. 
— «Thinking is seeing: visual metaphors and the nature of abstract thought», Semiotica, 1990, LXXX, III/IV, p. 221-237.

Delbecque Nicole \& Hanegreefs Hilde, "Escrutamos o escudriñamos un corpus?: dos conceptualizaciones diferentes», Signo \& Seña, 2006, XV, p. 187-229.

Demonte Violeta, Detrás de la palabra. Estudios de gramática del español, Madrid, Alianza Editorial, 1991.

Dowty David, «Thematic Proto-Roles and Argument Selection», Language, 1991, VVII, III, 547-619.

Enghels Renata, Les modalités de perception visuelle et auditive. Différences conceptuelles et répercussions sémantico-syntaxiques en espagnol et en français, Tübingen, Max Niemeyer Verlag, 2007.

Fernández Jaén Jorge, «Verbos de percepción sensorial en español: una clasificación cognitiva», Interlingüistica, 2006, XVI, p. 1-14.

- «Modalidad epistémica y sentido del olfato: la evidencialidad del verbo oler», ELUA, 2008, XXII, p. 65-89.

Fernández Lagunilla Marina, «Relaciones entre el léxico y la sintaxis: a propósito de vern, en De Miguel Elena (et al.) (eds.), Estructuras Léxicas y Estructura del Léxico, Frankfurt, Peter Lang, 2006, p. 347-367.

García-Miguel José María, "Aproximación empírica a la interacción de verbos y esquemas construccionales, ejemplificada con los verbos de percepción», ELUA, 2005, IXX, p. 169-191.

Geeraerts Dirk, Cognitive linguistics: basic readings, Berlin, Mouton de Gruyter, 2006.

Grezka Aude, «Études du lexique de la perception: bilan et perspectives», Contemporary Linguistics, 2006, LXI, p. 45-67.

Hanegreefs Hilde, «La interrelación entre semántica y sintaxis: problemas candentes en la clasificación de los complementos preposicionales con miran, en Trotter David (ed.), Actes du XXIVE Congrès International de Linguistique et de Philologie Romanes, Aberystwyth, 1-6 août 2004, Vol. IV, Tübingen, Max Niemeyer Verlag, 2007, p. 93105.

- Los verbos de percepción visual. Un análisis de corpus en un marco cognitivo, Tesis doctoral inédita, Katholieke Universiteit Leuven, 2008.

Horno Chéliz María del Carmen, «La interpretación estativa de la percepción visual desde un punto de vista tipológico», en Moreno Sandoval Antonio (ed.), Actas del VIII Congreso de Lingüistica General, Madrid, UAM, 2008, p. 995-1013.

Ibarretxe-Antuñano Iraide, Polysemy and Metaphor in Perception Verbs: a Cross-Linguistic Study, Tesis doctoral ineditado, University of Edinburg, 1999.

— «El cómo y el porqué de la polisemia de los verbos de percepción», en Molina Clara. (et al.) (eds.), Cognitive Linguistics in Spain at the turn of the century, Madrid, Universidad Autónoma de Madrid, 2003, p. 213-228.

— "Vision Metaphors for the Intellect: Are they Really Cross-Linguistic?», Atlantis. Journal of the Spanish Association of Anglo-American Studies, 2008, XXX, p. 15-33.

Lakoff George, Women, Fire, and Dangerous Things. What Categories Reveal about the Mind, Chicago/London, The University of Chicago Press, 1987.

Lakoff George \& Johnson Mark, Metaphors We Live By, Chicago, University Chicago Press, 1980.

Langacker Ronald W., Foundations of Cognitive Grammar Vol. I. Theoretical Prerequisites, Stanford, Stanford University Press, 1987.

- Foundations of Cognitive Grammar Vol. II. Descriptive Application, Stanford, Stanford University Press, 1991. 
- Grammar and Conceptualization, Berlin/New York, Mouton de Gruyter, 1999.

Mendikoetxea Amaya, "Construcciones inacusativas y pasivas», en Bosque Ignacio \& Demonte Violeta (eds.), Gramática Descriptiva de la Lengua Española, Madrid, Espasa Calpe, 1999, p. 1575-1629.

Peirsman Yves \& Geeraerts Dirk, "Metonymy as a prototypical category», Cognitive Linguistics, 2006, XVII, III, p. 269-316.

Rodríguez Espiñeira María José, «Percepción directa e indirecta en español. Diferencias semánticas y formales», Verba, 2000, XXVII, p. 33-85.

- Lecciones de sintaxis española, Santiago de Compostela, Universidade de Santiago de Compostela, 2004.

Roegiest Eugeen, "Argument Structure of Perception Verbs and Actance Variation of the Spanish Direct Object», en Fiorentino Guiliana (ed.), Romance Objects. Transitivity in Romance Languages, Berlin/New York, Mouton de Gruyter, 2003, p. 299-322.

Sabban Annette, «Polysemie und Kognitive Semantik - am Beispiel französischer und spanischer Verben der Wahrnehmung», Zeitschrift für französische Sprache und Literatur, 1994, CIV, 227-251.

Seco Manuel (et al.), Diccionario del Español Actual, Madrid, Aguilar, 1999.

Soares da Silva Augusto, «Imagery in portuguese causation/perception constructions», en Lewandowska-Tomaszczyk Barbara \& Kwiatkowska Alina (eds.), Imagery in Language. Festschrift in Honour of Professor Ronald W. Langacker, Frankfurt, Peter Lang, 2004, p. 297-319.

Sweetser Eve, From Etymology to Pragmatics. Metaphorical and Cultural Aspects of Semantic Structure, Cambridge, Cambridge University Press, 1990.

Talmy Leonard, Toward a Cognitive Semantics. Volume I: Concept Structuring Systems, Cambridge/Massachusetts, The MIT Press, 2000.

Taylor John R., «Meaning and context», en Cuyckens Hubert (et al.) (eds.), Motivation in language, Amsterdam/Philadelphia, John Benjamins Publishing Company, 2003, p. $27-48$.

Van Valin Robert D. \& LaPolla Randy J., Syntax. Structure, Meaning and Function, Cambridge, Cambridge University Press, 1997.

Vendler Zeno, Linguistics in Philosophy, Ithaca, Cornell University Press, 1967.

Viberg Åke, "The verbs of perception: a typological study», en Butterworth Brian (et al.) (eds.), Explanations for language universals, Berlin, Mouton de Gruyter, 1984, p. 123-162. 